\title{
Asset Prices in a Huggett Economy*
}

\author{
Per Krusell Toshihiko Mukoyama Anthony A. Smith, Jr. \\ September 2009
}

\begin{abstract}
This paper explores the asset-price implications in economies where there is no direct insurance against idiosyncratic risks but where there are other assetssuch as a riskfree bond or equity - that can be used for self-insurance, subject to exogenously imposed borrowing limits. We analyze an economy without production - an endowment economy - and we consider both the case with no aggregate risk and the case with aggregate risk. Thus, we analyze the economy originally studied, in the case without aggregate risk, in Huggett (1993). Our main innovation is that, by studying the case with "maximally tight" borrowing constraints, we can obtain full analytical tractability. Thus, like in Lucas's seminal asset-pricing paper, we obtain closed forms for all state-contingent claims, allowing us to study the price determination for all assets with payoffs contingent on aggregate events. In the Huggett economy, like in Lucas's, any asset pricing is obtained using a first-order condition, but in the Huggett economy only a subset of the consumers will typically have first-order constraints holding with equality - the others are borrowing-constrained. Thus, the analysis centers around who prices the assets, and around what the endowment risks of this agent are; in the Lucas economy, only the aggregate endowment risk matters. Moreover, identity/type of the consumer pricing an asset may change over time. We specifically illustrate by looking at riskless bonds, equity, and the term structure of interest rates, and we show that the model with tight constraints can reproduce observed features of asset prices when idiosyncratic risks are quantitatively reasonable.
\end{abstract}

*The authors acknowledge helpful comments from participants at the 2008 Midwest Macro Meetings and at the Murray S. Johnson Memorial Conference in honor of Truman F. Bewley, held at the University of Texas at Austin in April 2009. Krusell is at the Institute for International Economic Studies, CAERP, CEPR, and NBER; Mukoyama is at the University of Virginia and CIREQ; Smith is at Yale University. 


\section{Introduction}

Are some of the striking features of asset prices - in particular, the high premium for risk in asset markets and the low return on risk-free assets - a result of market incompleteness and, in particular, of missing markets for consumers' idiosyncratic risks? This possibility was raised in the concluding remarks of the seminal paper by Mehra and Prescott (1985), and it was subsequently investigated by many researchers, among them Mankiw (1986), Heaton and Lucas (1992, 1996), Huggett (1993), Telmer (1993), Lucas (1994), den Haan (1996), Constantinides and Duffie (1996), Krusell and Smith (1997), Marcet and Singleton (1999), Storesletten, Telmer, and Yaron (2007). Some of these analyses suggest that the effects of market incompleteness can be quantitatively important - e.g., the work by Constantinides and Duffie and by Storesletten, Telmer, and Yaron-but the "average view" in this literature is probably closer to concluding that no major aspects of asset prices are overturned if market incompleteness is taken into account. In fact, a recent study by Krueger and Lustig (2007) demonstrates that in a range of interesting cases, risk premia will not be affected at all by market incompleteness, even though the risk-free rate might be.

A general challenge in this literature has been that multiperiod equilibrium models where agents are faced with less than fully insurable idiosyncratic risks are hard to analyze, even with the aid of numerical methods. The present paper explores Huggett's setting and manages to obtain closed-form solutions for asset prices in a special, but illuminating, case, namely the case where the borrowing constraints are "maximally tight." This case is of particular interest, because the tighter is the borrowing constraint, the more "bite" will the market incompleteness have in terms of producing asset prices that are different from those obtaining in the standard representative-agent model. One could thus view our present setting as one that allows us to examine the potential of incomplete-markets settings for explaining asset prices. We demonstrate how the different primitives of the model - the discount rate, the preference curvature, and the endowment process - influence prices. In particular, we show that the model allows a very rich set of asset-price predictions, including large equity premia, a low 
risk-free rate, and a yield curve that is qualitatively different than in the standard model.

The Huggett economy is the simplest form of endowment economy. In Huggett's (1993) paper, only a riskless asset is available to agents, who are thus using this asset for precautionary saving against endowment shocks. There is no aggregate risk: the aggregate endowment is constant over time. Huggett shows, using numerical analysis, that with high curvature in utility and a tight enough borrowing constraint, the riskfree rate can be significantly below the discount rate: agents value the riskless asset not only for its direct return but for its value as an insurance instrument. Our analytical power comes from the insight that if the borrowing constraint is maximally tight, implying that no borrowing at all is possible, the equilibrium has to be autarky. In autarky, the bond price will have to be equal to that of the agent in the population who values the bond the most: all other consumers would like to hold a negative amount of bonds (but cannot), and the bond-pricing consumer is just indifferent at zero bond holdings. In very simple settings with a two-state endowment process, which we spend most of the paper analyzing, it is obvious who values the bond the most - it is the consumer with the high endowment-but for general endowment processes it is not obvious.

Moreover, in a Huggett economy with aggregate risk (like that studied by den Haan), we can similarly look at the case with maximally tight borrowing constraints by assuming that for every asset contingent on the aggregate state, no negative holding is allowed, again implying that equilibrium is autarky and that each state-contingent asset is priced by the agent in the population who values it the most. Thus, overall, asset prices in our Huggett economy are determined in the same manner as are those in Lucas's (1978) exchange economy - so that all markets for contingent claims clear at zero - although here only one type of consumer has an interior asset demand for each asset, whereas in Lucas's setting all agents (i.e., the representative agent) have interior solutions for all assets. We thus derive explicit, easy-to-interpret formulas for all claims contingent on aggregate shocks, and thus any assets with payoffs contingent on aggregate shocks can be priced. As an illustration, we show how to derive predictions 
for the term structure of interest rates; as in Lucas's work, these are easily priced using the contingent-claims prices. Few existing studies in this literature manage to look at a very rich set of assets, since the numerical analysis of portfolio choice of models with incomplete markets with aggregate risk is quite challenging. A case of special interest is that where the long-term bonds are not fully liquid; for illustration we analyze the case where the secondary markets are absent. For this economy we show that, even in the absence of aggregate risk, there is a non-trivial yield curve, and this yield curve is upward-sloping under a reasonable calibration.

Other studies before ours manage to characterize equilibria analytically in specific incomplete-markets settings. Krueger and Lustig are able to characterize risk premia by assuming a form of independence between idiosyncratic and aggregate shocks; Constantinides and Duffie, on the other hand, use a setting with literally permanent shocks and are able to characterize prices that way (since autarky is an equilibrium in that case as well). Krueger and Lustig's results apply in a special case of our setting, if we make the appropriate independence assumptions. Constantinides and Duffie's results are not a special case of our setting, because we model endowment shocks using stationary Markov chains, but nothing prevents an extension of our setting to such cases. We emphasize stationary processes not only because some argue that this is more realistic, but because it allows us to show explicitly how the degree of persistence in individual endowments influences asset prices.

Our work is related in some respects to the work of Alvarez and Jermann (2000, 2001), who study asset pricing with endogenous solvency constraints. For some settings of parameter values, they find that the equilibrium allocation features less-than-full, or even no, risk sharing. In these cases, as in our work, asset prices are determined by a subset of consumers - those who value the asset the most - rather than by the average consumer. Alvarez and Jermann must solve a constrained planning problem using numerical methods to compute equilibrium allocations. By imposing no risk sharing from the outset, we gain full analytical tractability, so that our setup is both simpler and more transparent. This analytical tractability allows us to gain sharp insights about how fundamentals affect asset prices. Moreover, our analytical characterization 
of equilibria allows us to prove a result analogous to the one in Constantinides and Duffie (1996); in particular, by judicious choice of the process for idiosyncratic risk we can reproduce any pricing kernel, provided it satisfies the same restriction as in Constantinides and Duffie (1996).

Of course, unlike Alvarez and Jermann, we do not derive our borrowing constraints from fundamentals; here, we leave open the reasons why these constraints are present. For the question at hand, this is perhaps not such a major drawback, since our goal is to find an "upper bound" of the effects of market incompleteness, whatever its sources might be, given the preferences and endowment processes of consumers.

Our model allows very general preference and endowment settings; we discuss extensions in the final section of our paper. We begin the analysis in the paper in Section 2 with the simplest case: the revisiting of Huggett's analysis without aggregate uncertainty, obtaining an analytical solution for the price of the riskless bond. We then look at aggregate uncertainty in Section 3 and explore the quantitative implications of our model. For simplicity, throughout both of these sections we restrict attention to the case with only two possible states for individual risk. In Section 4 we look at more than two states, which is a case of interest because it is then less clear who prices each asset. Section 5 concludes.

\section{The economy without aggregate uncertainty}

In this section, we analyze the model of Huggett (1993). Consider an exchange economy where each consumer receives a random nondurable endowment every period. There is a continuum of consumers with total population of one. In this section, we focus on the steady state where the aggregate variables are constant and the distribution of the individual states is stationary. In this and the following section, we assume that the endowment follows a two-point process. In Section 4, we extend our analysis to a setting where there are more than two possible values of the endowment. 


\section{$2.1 \quad$ Model}

The consumers cannot write contracts that depends on individual idiosyncratic states. Instead, they are allowed to borrow and lend through selling and buying bonds. The bond holding is denoted by $a$ and the price of a bond that delivers one unit of consumption good next period is denoted by $q$.

A consumer maximizes the expected present-value of utility:

$$
E\left[\sum_{t=0}^{\infty} \beta^{t} u\left(c_{t}\right)\right],
$$

where $u(\cdot)$ is the momentary utility function, $c_{t}$ is the consumption at period $t$, and $\beta \in(0,1)$. Following Huggett (1993), we consider the specification

$$
u(c)=\frac{c^{1-\sigma}}{1-\sigma},
$$

where $\sigma>1$.

Using recursive notation (a “'” denotes next period's value),

$$
c+q a^{\prime}=a+\epsilon
$$

where $\epsilon$ is the random endowment. We let $\epsilon$ take on two values, $\epsilon_{\ell}$ and $\epsilon_{h}$, where $\epsilon_{\ell}<\epsilon_{h}$. It follows a Markov process with transition probability $\operatorname{Pr}\left[\epsilon^{\prime}=\epsilon_{s^{\prime}} \mid \epsilon=\epsilon_{s}\right]=\pi_{s s^{\prime}}$. We impose a borrowing constraint

$$
a^{\prime} \geq \underline{a}
$$

where $\underline{a} \leq 0$ is a given constant.

The consumer's Bellman equation is

$$
V_{s}(a)=\max _{c, a^{\prime}} \frac{c^{1-\sigma}}{1-\sigma}+\beta\left[\pi_{s h} V_{h}\left(a^{\prime}\right)+\left(1-\pi_{s h}\right) V_{\ell}\left(a^{\prime}\right)\right]
$$

subject to

$$
c=a+\epsilon_{s}-q a^{\prime}
$$

and

$$
a^{\prime} \geq \underline{a}
$$


Here, $V_{s}(a)$ is the value function of a consumer with the endowment $\epsilon_{s}$ and the bond holding $a$. Let the decision rule of the consumer be $a^{\prime}=\psi(a ; s)$.

The stationary equilibrium is defined by the consumer's optimization and the value of $q$, where

$$
\sum_{s=\ell, h} \int \psi(a ; s) \Gamma_{s}(d a)=0
$$

and where $\Gamma_{s}(a)$ is the stationary distribution of asset holdings for the consumers with endowment $\epsilon_{s}$.

In the following, we consider the special case of $\underline{a}=0$. The implication of this assumption is that, since nobody can borrow and (1) has to hold, nobody can save in equilibrium: $\psi(0 ; s)=0$ for all $s$. One does not need to characterize $\psi(a ; s)$ for other values of $a$, since the stationary distribution over $a$ has all its mass on 0 in this special case. Thus, in equilibrium, for each $s$, consumption equals $\epsilon_{s}$ for all agents in state $s$.

\subsubsection{Assets in positive demand}

Note that above, as in Huggett (1993), we assume that there is no asset that is in positive net supply. In this section we show that this assumption can easily be relaxed. Suppose that there is an asset, called a "tree," that generates a constant amount $\eta$ every period. ${ }^{1}$ Let the price of the tree be $p$ and the individual holding of the tree be $x$. Then the individual consumer's problem becomes

$$
V_{s}(a, x)=\max _{c, a^{\prime}, x^{\prime}} \frac{c^{1-\sigma}}{1-\sigma}+\beta\left[\pi_{s h} V_{h}\left(a^{\prime}, x^{\prime}\right)+\left(1-\pi_{s h}\right) V_{\ell}\left(a^{\prime}, x^{\prime}\right)\right]
$$

subject to

$$
c=a+(\eta+p) x+\epsilon_{s}-q a^{\prime}-p x^{\prime}
$$

In equilibrium, the bond and the tree have to generate the same return, so $(p+\eta) / p=$ $1 / q$. Therefore, $q=p /(\eta+p)$ holds. Using this, the budget constraint can be rewritten as

$$
c=(\eta+p)\left(\frac{a}{\eta+p}+x\right)+\epsilon_{s}-p\left(\frac{a^{\prime}}{\eta+p}+x^{\prime}\right) .
$$

\footnotetext{
${ }^{1} \mathrm{~A}$ similar argument can be made if there is a constant positive supply of outside, say government, bonds, with an associated government budget constraint.
} 
Let $\hat{a} \equiv a /(\eta+p)+x$. Then the problem can be rewritten as

$$
V_{s}(\hat{a})=\max _{c, \hat{a}^{\prime}} \frac{c^{1-\sigma}}{1-\sigma}+\beta\left[\pi_{s h} V_{h}\left(\hat{a}^{\prime}\right)+\left(1-\pi_{s h}\right) V_{\ell}\left(\hat{a}^{\prime}\right)\right]
$$

subject to

$$
c=(\eta+p) \hat{a}+\epsilon_{s}-p \hat{a}^{\prime}
$$

Now, suppose that the borrowing constraint is $\hat{a} \geq 1$, i.e., we use a borrowing constraint on total wealth rather than on the holdings of individual assets. Below, we will show that the equilibrium is that $\hat{a}=1$ for everyone. One allocation that achieves this is $a=0$ and $x=1$ for everyone - that is, no one holds bonds and everyone owns the same amount of the tree. Other asset holding patterns are also possible- some can hold $a<0$ and $x>1$ while others can have $a>0$ and $x<1$. The only requirements for an equilibrium are that $\hat{a}=1$ for everyone, $a$ sums up to zero, and $x$ sums up to one.

To show that $\hat{a}=1$ for everyone is the only equilibrium, define $\tilde{a} \equiv p(\hat{a}-1) / q$ and $\tilde{\epsilon}_{s} \equiv \epsilon_{s}+\eta$. Then the problem becomes

$$
V_{s}(\tilde{a})=\max _{c, \tilde{a}^{\prime}} \frac{c^{1-\sigma}}{1-\sigma}+\beta\left[\pi_{s h} V_{h}\left(\tilde{a}^{\prime}\right)+\left(1-\pi_{s h}\right) V_{\ell}\left(\tilde{a}^{\prime}\right)\right]
$$

subject to

$$
c=\tilde{a}+\tilde{\epsilon}_{s}-q \tilde{a}^{\prime}
$$

and

$$
\tilde{a} \geq 0
$$

which is identical to the original problem. Therefore, the equilibrium is autarky: $\tilde{a}=0$ and $c=\tilde{\epsilon}_{s} . \quad \tilde{a}=0$ implies $\hat{a}=1$. As long as the borrowing constraint is set at an appropriate level, we can transform an economy where there are assets in positive net supply into an economy with a bond in zero net supply. Thus, the borrowing constraint here means that agents have to have at least a certain (positive) amount of the asset. We do not suggest that such an assumption is reasonable per se. Rather, the approach in this paper throughout is to derive asset prices in incomplete-markets economies for the case where the borrowing constraint is "maximally tight", and we have just seen 
that, when the asset is in positive net supply, the maximally tight constraint is positive, so that any given borrowing constraint is less constraining than in the case where the asset is in zero net supply. Thus, we can use the results in this paper, even when the assets are in positive net supply, as "upper bounds" for how different asset prices can be in the incomplete-markets economy than in a representative-agent economy. The analysis in the present section then simply suggests that we may be further from these upper bounds (and thus closer to representative-agent asset pricing) when the assets are in positive net supply, to the extent we think that the borrowing constraints on such assets are similar to those on assets in zero net supply.

\subsection{Determination of the equilibrium bond price}

In this section, we characterize the equilibrium bond price. Let $\lambda_{s} \geq 0$ be the Lagrange multiplier for the borrowing constraint when $\epsilon=\epsilon_{s}$.

The first-order conditions for the consumers are

$$
-q c_{s}^{-\sigma}+\beta\left[\pi_{s h} V_{h}^{\prime}\left(a^{\prime}\right)+\left(1-\pi_{s h}\right) V_{\ell}^{\prime}\left(a^{\prime}\right)\right]+\lambda_{s}=0,
$$

for $s=h, \ell$. Here, $c_{s}$ is the optimal $c$ when $\epsilon=\epsilon_{s} . V_{s}^{\prime}(a)$ is the derivative of $V_{s}(a)$ with respect to $a$. The envelope condition is

$$
V_{s}^{\prime}(a)=c_{s}^{-\sigma}
$$

Noting that $c_{s}=\epsilon_{s}$ in equilibrium, (2) can be rewritten as

$$
\frac{q}{\beta}-\frac{\lambda_{h}}{\beta \epsilon_{h}^{-\sigma}}=\pi_{h h}+\left(1-\pi_{h h}\right)\left(\frac{\epsilon_{\ell}}{\epsilon_{h}}\right)^{-\sigma}
$$

and

$$
\frac{q}{\beta}-\frac{\lambda_{\ell}}{\beta \epsilon_{\ell}^{-\sigma}}=\pi_{\ell h}\left(\frac{\epsilon_{h}}{\epsilon_{\ell}}\right)^{-\sigma}+1-\pi_{\ell h} .
$$

Since the right-hand side of (3) is larger than one and the right-hand side of (4) is less than one,

$$
\frac{\lambda_{h}}{\beta \epsilon_{h}^{-\sigma}}<\frac{\lambda_{\ell}}{\beta \epsilon_{\ell}^{-\sigma}}
$$


follows. Therefore, $\lambda_{\ell}>0$ and the borrowing constraint is always binding for the consumers with $s=\ell$. Thus, it is sufficient for an equilibrium that $\lambda_{h} \geq 0$ is satisfied. From (3), we can characterize the bond price $q$ as follows.

Proposition 1 The bond price q satisfies

$$
q \geq q^{*} \equiv \beta\left[\pi_{h h}+\left(1-\pi_{h h}\right)\left(\frac{\epsilon_{h}}{\epsilon_{\ell}}\right)^{\sigma}\right] .
$$

Any bond price $q$ that satisfies (5) is consistent with the consumers' optimization and the bond-market equilibrium (1), and thus constitutes an equilibrium. Note that the right-hand side of (5) is always strictly larger than $\beta$, so the risk-free rate is always strictly less than $1 / \beta-1$.

The lower-bound of the equilibrium bond prices, $q^{*}$, is of particular interest since it is the limit of the equilibrium bond prices when $\underline{a}$ approaches zero from below, provided that the equilibrium bond price varies continuously with $\underline{a}{ }^{2}$ Below, we assume that $q$ is equal to $q^{*}$, and characterize $q^{*}$.

\subsection{Comparative statics}

Equation (5) shows that $q^{*}$ can be characterized by the marginal utility of the highendowment consumers. It also shows the role of various parameters in determining the equilibrium bond price. $q^{*}$ is increasing in $\beta, \sigma$, and $\epsilon_{h} / \epsilon_{\ell}$. It is decreasing in $\pi_{h h}$ : when the high-endowment state is permanent, there is less of a precautionary-saving motive and $q^{*}$ becomes small.

In the context of Huggett (1993), this expression clarifies the role of $\sigma$ in determining the precautionary-saving motive. This mechanism helps solve the risk-free rate puzzle by Weil (1989); here, a high $\sigma$ is consistent with a low risk-free rate. To see this, suppose that the endowment grows over time: let the endowment be $(1+g)^{t} \epsilon$, where $\epsilon$ has the

\footnotetext{
${ }^{2}$ This can be proved as follows. If $q$ converges to a value below $q^{*}$, then in the neighborhood of this converged value, there is a strictly positive bond demand from the high-endowment agent, while the supply of the bond is close to zero because of the borrowing constraint, and therefore the bond market cannot be in equilibrium. If $q$ converges to a value above $q^{*}$, then in the neighborhood of this value there is a strictly negative aggregate bond demand, which implies that everyone becomes borrowing-constrained, again contradicting bond-market equilibrium.
} 
same properties as before. Then, the equilibrium price of the bond becomes $(1+g)^{-\sigma} q^{*}$, where $q^{*}$ corresponds to the price in the absence of growth. In the complete-markets model, $q^{*}$ would equal $\beta$, and therefore a positive $g$ and a large value of $\sigma$ imply a very low bond price. Thus, since the risk-free rate is the inverse of the bond price, when we consider a growing economy, the complete-markets risk-free rate would be very large, contradicting observation (this is the risk-free rate puzzle). In the current model, however, the precautionary-saving motive increases the bond price, and this can offset the effect of growth. In the incomplete-markets case, $q^{*}$ is increasing in $\sigma$. Thus, with growth, the bond price can either be increasing or decreasing in $\sigma$ in the incomplete-markets model. Figure 1 plots the equilibrium bond prices for various values of $\sigma$, when $\beta=0.98, g=0.01, \pi_{h h}=0.9$, and $\epsilon_{h} / \epsilon_{\ell}=1.08$, illustrating that the riskfree rate is increasing in $\sigma$ for low $\sigma$ and decreasing in $\sigma$ for higher $\sigma$.

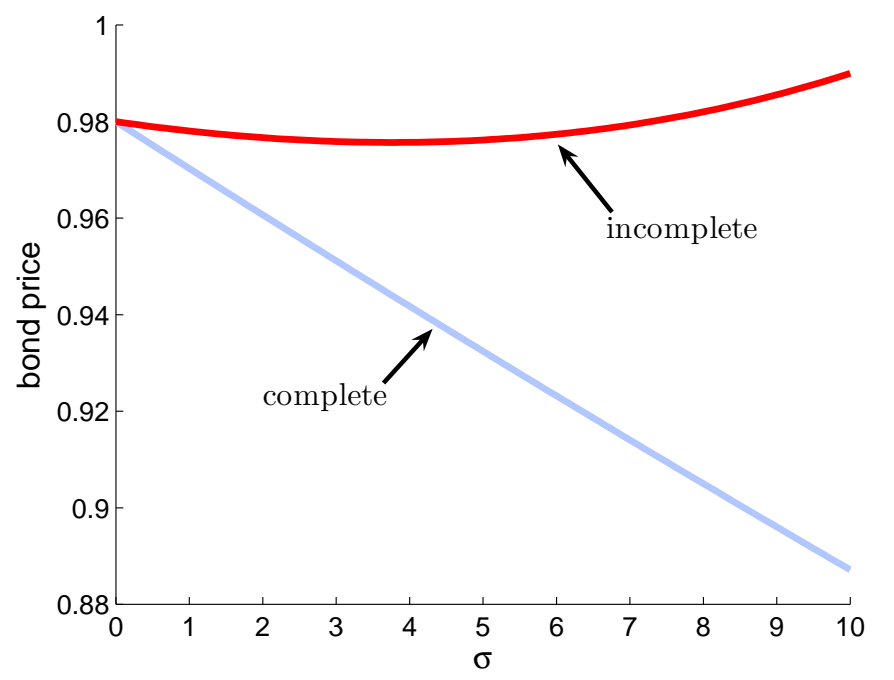

Figure 1: Bond prices for various values of $\sigma$ 


\subsection{A note on transactions costs in "secondary" markets}

With this model, one can also price other kinds of assets. When there is no aggregate risk, another kind of asset that might be priced is a long-term riskless bond, i.e., a bond that pays one unit of consumption for sure in a future period $n$. Consider $n=2$ for simplicity: what is the issue price of a two-period riskless bond? To the extent it is traded in the intermediate period, it must be $\left(q^{*}\right)^{2}$, from the usual arbitrage arguments. However, suppose that there are transactions costs, so that the two-period bond cannot be re-traded in the intermediate period: the "secondary" market is not operative. Suppose, moreover, that the two-period bond has the same kind of maximally tight borrowing constraint as does the one-period bond: it cannot be issued by individuals (they cannot use it to borrow), but it can be held in positive amounts. Given a zero net supply, no one will hold the two-period bond in equilibrium, however, and equilibrium is still autarky, allowing us to price the assets as easily as before. The one-period riskless bond will, as before, be priced by the rich agent, so it will command the price $q^{*}$. The two-period bond will also be priced by the rich agent, who is the only agent with the chance of a consumption drop between now and two periods from now. Thus, it will have a price $q^{(2)}$ satisfying

$$
q^{(2)}=\beta^{2}\left[\pi_{h h}^{(2)}+\left(1-\pi_{h h}^{(2)}\right)\left(\frac{\epsilon_{h}}{\epsilon_{\ell}}\right)^{\sigma}\right],
$$

where $\pi_{h h}^{(2)} \equiv \pi_{h h}^{2}+\left(1-\pi_{h h}\right) \pi_{\ell h}$ is the probability of transiting from $h$ to $h$ in two periods. Longer-period bonds subject to no re-trading can be priced similarly.

What will the term structure of interest rate look like in our incomplete-markets economy without secondary markets for bonds? We see that $q^{(2)}<\left(q^{*}\right)^{2}$, so that the longer-period bond gives a higher return (the yield curve is upward-sloping), if and only if

$$
\pi_{h h}^{(2)}+\left(1-\pi_{h h}^{(2)}\right)\left(\frac{\epsilon_{h}}{\epsilon_{\ell}}\right)^{\sigma}<\left[\pi_{h h}+\left(1-\pi_{h h}\right)\left(\frac{\epsilon_{h}}{\epsilon_{\ell}}\right)^{\sigma}\right]^{2} .
$$

Thus, we obtain a nontrivial yield curve. Inspecting the expression, if the endowment process has positive serial correlation (which is reasonable to assume), implying $\pi_{h h} \geq$ $\pi_{h h}^{(2)}$, then given any given value of $\left(\frac{\epsilon_{h}}{\epsilon_{\ell}}\right)^{\sigma}>1$, the yield curve is upward-sloping if the 
process is not mean-reverting too quickly. Also note that for an iid process, we always obtain a positive slope on the yield curve.

\section{The economy with aggregate uncertainty}

In this section, we extend the basic model by incorporating aggregate uncertainty. Suppose that there are two aggregate states, $Z \in\{g, b\}$. There are two Arrow securities: a state- $z^{\prime}$ security, purchased at the price $Q_{z z^{\prime}}$ when the current state is $z$, delivers one unit of consumption good next period when the next period's aggregate state is $z^{\prime}$. Note that the aggregate states are spanned by these securities, but that the market is still incomplete: idiosyncratic risks cannot be insured away. ${ }^{3}$

The introduction of this type of securities has two virtues. First, any asset whose returns depend only on the aggregate state can be priced uniquely by the prices of these securities. Second, we can introduce the borrowing constraint in a natural manner, since the holdings of these securities is directly linked to the total asset balance in the following period. ${ }^{4}$

\subsection{Model}

The consumer's problem is now to maximize

$$
E\left[\sum_{t=0}^{\infty} \beta^{t} \frac{c_{t}^{1-\sigma}}{1-\sigma}\right]
$$

\footnotetext{
${ }^{3}$ Any two independent securities can replicate the Arrow securities here. For example, suppose that there is infinitely-lived "equity" which delivers $e_{z}$ in state $z$ and a one-period bond which delivers 1 unit in both future states. Denoting $x$ as the equity demand, $p_{z}$ as the equity price, and $y$ as the bond demand,

$$
a_{g}^{\prime}=\left(p_{g}+e_{g}\right) x^{\prime}+y^{\prime}
$$

and

$$
a_{b}^{\prime}=\left(p_{b}+e_{b}\right) x^{\prime}+y^{\prime}
$$

hold. From these equations, it can be seen that a $g$-state Arrow security can be replicated by combining $1 /\left(p_{g}+e_{g}-p_{b}-e_{b}\right)$ units of equity and $\left(-p_{b}-e_{b}\right) /\left(p_{g}+e_{g}-p_{b}-e_{b}\right)$ units of bond, and a $b$-state Arrow security can be replicated by combining $1 /\left(p_{b}+e_{b}-p_{g}-e_{g}\right)$ units of equity and $\left(-p_{g}-e_{g}\right) /\left(p_{b}+\right.$ $e_{b}-p_{g}-e_{g}$ ) units of bond.

${ }^{4}$ As in the previous section, assets with net positive supply can easily be introduced by setting the borrowing constraints appropriately.
} 
subject to the (recursively stated) constraints

$$
c+Q_{Z g} a_{g}^{\prime}+Q_{Z b} a_{b}^{\prime}=a_{Z}+\epsilon
$$

and

$$
a_{g}^{\prime} \geq 0, a_{b}^{\prime} \geq 0
$$

Here, $a_{z^{\prime}}$ is the amount of state- $z^{\prime}$ security held by the consumer. Asset-market equilibrium requires the sum of net demands for $a_{z^{\prime}}^{\prime}$ to be zero for $z^{\prime}=g, b$. As in the previous section, in equilibrium nobody can borrow, so nobody can save, and therefore the equilibrium is autarky.

We assume, as before, that the endowment can only have two values: $\epsilon \in\left\{\epsilon_{h}, \epsilon_{\ell}\right\}$ where $\epsilon_{h}>\epsilon_{\ell}$. Let $\operatorname{Pr}\left[Z^{\prime}=z^{\prime} \mid Z=z\right]=\phi_{z z^{\prime}}$ and $\operatorname{Pr}\left[\epsilon=\epsilon_{s^{\prime}} \mid \epsilon=\epsilon_{s}, Z=z, Z^{\prime}=z^{\prime}\right]=$ $\pi_{s s^{\prime} \mid z z^{\prime}}$. Then the consumer's Bellman equation is

$$
V(a ; s, z)=\max _{c, a_{g}^{\prime}, a_{b}^{\prime}} \frac{c^{1-\sigma}}{1-\sigma}+\beta\left[\sum_{z^{\prime}=g, b} \phi_{z z^{\prime}}\left[\pi_{s h \mid z z^{\prime}} V\left(a_{z^{\prime}}^{\prime} ; h, z^{\prime}\right)+\left(1-\pi_{s h \mid z z^{\prime}}\right) V\left(a_{z^{\prime}}^{\prime} ; \ell, z^{\prime}\right)\right]\right]
$$

subject to

$$
c=a+\epsilon_{s}-Q_{z g} a_{g}^{\prime}-Q_{z b} a_{b}^{\prime}
$$

and

$$
a_{g}^{\prime} \geq 0, a_{b}^{\prime} \geq 0
$$

Let $\lambda_{s z}^{z^{\prime}}$ be the Lagrange multiplier for the borrowing constraint for the state- $z^{\prime}$ security when the current state is $s$ and $z$. The first-order condition is

$$
-Q_{z z^{\prime}} c_{s z}^{-\sigma}+\beta \phi_{z z^{\prime}}\left[\pi_{s h \mid z z^{\prime}} V^{\prime}\left(a_{z^{\prime}}^{\prime} ; h, z^{\prime}\right)+\left(1-\pi_{s h \mid z g}\right) V^{\prime}\left(a_{z^{\prime}}^{\prime} ; \ell, z^{\prime}\right)\right]+\lambda_{s z}^{z^{\prime}}=0
$$

where $c_{s z}$ is consumption of the consumer whose individual state is $s$ when the aggregate state is $z$.

The envelope conditions are

$$
V^{\prime}(a ; s, z)=c_{s z}^{-\sigma}
$$




\subsection{The prices of contingent claims}

Recall that $c_{s z}=\epsilon_{s}$ in equilibrium. To determine $Q_{z z^{\prime}}$, let us look at (6). For each $\left(z, z^{\prime}\right)$, there are two first-order conditions (for $s=h$ and $s=\ell$ ). They can be rewritten as

$$
\frac{Q_{z z^{\prime}}}{\beta \phi_{z z^{\prime}}}-\frac{\lambda_{h z}^{z^{\prime}}}{\beta \phi_{z z^{\prime}} \epsilon_{h}^{-\sigma}}=\pi_{h h \mid z z^{\prime}}+\left(1-\pi_{h h \mid z z^{\prime}}\right)\left(\frac{\epsilon_{\ell}}{\epsilon_{h}}\right)^{-\sigma}
$$

and

$$
\frac{Q_{z z^{\prime}}}{\beta \phi_{z z^{\prime}}}-\frac{\lambda_{\ell z}^{z^{\prime}}}{\beta \phi_{z z^{\prime}} \epsilon_{\ell}^{-\sigma}}=\pi_{\ell h \mid z z^{\prime}}\left(\frac{\epsilon_{h}}{\epsilon_{\ell}}\right)^{-\sigma}+\left(1-\pi_{\ell h \mid z z^{\prime}}\right) .
$$

Using the logic employed in the previous section, we conclude that

$$
\frac{\lambda_{h z}^{z^{\prime}}}{\beta \phi_{z z^{\prime}} \epsilon_{h}^{-\sigma}}<\frac{\lambda_{\ell z}^{z^{\prime}}}{\beta \phi_{z z^{\prime}} \epsilon_{\ell}^{-\sigma}}
$$

holds. Therefore, $\lambda_{\ell z}^{z^{\prime}}>0$ and the borrowing constraint is binding for the consumers with $s=\ell .5$ To satisfy $\lambda_{h z}^{z^{\prime}} \geq 0, Q_{z z^{\prime}}$ has to satisfy

$$
Q_{z z^{\prime}} \geq Q_{z z^{\prime}}^{*} \equiv \beta \phi_{z z^{\prime}}\left[\pi_{h h \mid z z^{\prime}}+\left(1-\pi_{h h \mid z z^{\prime}}\right)\left(\frac{\epsilon_{h}}{\epsilon_{\ell}}\right)^{\sigma}\right] .
$$

Again, we focus on the case where the asset prices are determined by the lower bound: $Q_{z z^{\prime}}=Q_{z z^{\prime}}^{*}$. Then, $Q_{z z^{\prime}}$ is increasing in $\beta, \phi_{z z^{\prime}}, \sigma$, and $\epsilon_{h} / \epsilon_{\ell}$. It is decreasing in $\pi_{h h \mid z z^{\prime}}$. In the following, we denote $\omega \equiv\left(\epsilon_{h} / \epsilon_{\ell}\right)^{\sigma}$. Note that $\omega>1$ and it is increasing in $\sigma$ and $\epsilon_{h} / \epsilon_{\ell}$. Also define

$$
m_{z z^{\prime}} \equiv \beta\left[\pi_{h h \mid z z^{\prime}}+\left(1-\pi_{h h \mid z z^{\prime}}\right) \omega\right]
$$

\subsubsection{The bond price}

Now we investigate the properties of bonds and stock in this economy. The bond price at state $z$ is

$$
q_{z}=\sum_{z^{\prime}=g, b} Q_{z z^{\prime}}=\sum_{z^{\prime}=g, b} \phi_{z z^{\prime}} m_{z z^{\prime}}=E\left[m_{z z^{\prime}}\right] .
$$

\footnotetext{
${ }^{5}$ This is not the case if we extend the model to allow the values of $\epsilon_{\ell}$ and $\epsilon_{h}$ to vary across aggregate states. In such a case, it is possible that high-endowment consumers are constrained when the aggregate state switches.
} 
In this section, all the expectations $E[\cdot]$, variances $\operatorname{Var}[\cdot]$, and covariances $\operatorname{Cov}(\cdot, \cdot)$ are with respect to $z^{\prime}$, conditional on $z$. The (gross) return from the bond (that is, risk-free rate) is $R_{z}^{f}=q_{z}^{-1}$. Thus,

$$
1=E\left[R_{z}^{f} m_{z z^{\prime}}\right]
$$

Note that from the definition of $m_{z z^{\prime}}$,

$$
q_{z}=\beta\left(\omega-(\omega-1) E\left[\pi_{h h \mid z z^{\prime}}\right]\right)
$$

This expression clarifies that, similarly to the previous section, the (average) level of $\pi_{h h \mid z z^{\prime}}$ is an important determinant of the bond price.

As a general proposition, in our environment prices are not a function of the process for aggregate consumption, as in representative-agent models. For example, as far as the cyclicality of the bond price, $q_{z}$, in our model it depends on how $E\left[\pi_{h h \mid z z^{\prime}}\right]$ behaves. In contrast, in a complete-markets environment, where we can identify a "representative agent," $q_{z}$ is always pro-cyclical: denoting the total endowment is $C_{z}$ in state $z$, we would obtain $q_{z}=\beta \sum_{z^{\prime}=b, g} \phi_{z z^{\prime}}\left(C_{z^{\prime}} / C_{z}\right)^{-\sigma}$. In our model, on the other hand, $q_{z}$ is pro-cyclical if and only if $E\left[\pi_{h h \mid g z^{\prime}}\right]<E\left[\pi_{h h \mid b z^{\prime}}\right]$, i.e., if the future endowment prospects of a rich consumer are better in bad aggregate times than in good aggregate times. More broadly, $q$ 's properties depend on the individual endowment process in a particular way, picking out a marginal rate of substitution of a specific individual at each point in time, and this individual is also not necessarily the same person over time. In the simple environment discussed in the present section, it is always the richest agent; in more complex environments (see Section 4), it may be an agent with an intermediate endowment level.

\subsubsection{The term structure of interest rates}

Any asset that depends only on the aggregate state can be priced by $Q_{z z^{\prime}}$. Here we consider a long-term riskless bond, in order to examine the implications for the term structure of interest rates. We assume, in contrast to the approach discussed in Section 2.4 , that the secondary markets for long-term bonds are perfect. Let $q_{z}^{(n)}$ be the price 
of $n$-period bond when the aggregate state is $z$. Recall that the price of a one-period bond is

$$
q_{z}^{(1)}=Q_{z g}+Q_{z b}
$$

We can construct the price of an $n$-period bond by combining the Arrow-securities and lower-horizon bonds from

$$
q_{z}^{(n)}=Q_{z g} q_{g}^{(n-1)}+Q_{z b} q_{b}^{(n-1)}
$$

recursively, with the known expression for $q^{(1)}$ above as starting condition.

To analyze the term structure, and focusing on the relation between a one- and a two-period bond, note that the net, per-period returns of these bonds are

$$
r_{z}^{(n)} \equiv\left(\frac{1}{q_{z}^{(n)}}\right)^{\frac{1}{n}}-1
$$

for $n=1,2$. Clearly, we have $r_{z}^{(1)}<r_{z}^{(2)}$ and an upward-sloping yield curve if and only if $q_{z}^{(2)}<\left(q_{z}^{(1)}\right)^{2}$, that is, if and only if

$$
\frac{q_{z}^{(2)}}{q_{z}^{(1)}}<q_{z}^{(1)}
$$

or, using (14) for $n=2$ on the left-hand side as well as (13) on the right-hand side, if and only if

$$
\frac{Q_{z g} q_{g}^{(1)}+Q_{z b} q_{b}^{(1)}}{q_{z}^{(1)}}<Q_{z g}+Q_{z b} .
$$

Applying this expression for $z=g$ and $z=b$ separately, the yield curve is upwardsloping in state $z=g$ if and only if

$$
q_{g}^{(1)}>q_{b}^{(1)}
$$

whereas it is upward-sloping in state $z=b$ if and only if

$$
q_{g}^{(1)}<q_{b}^{(1)}
$$

Thus, if $q_{g}^{(1)}>q_{b}^{(1)}$, so that the short-term bond price is pro-cyclical (the shortterm interest rate is counter-cyclical), the yield curve is upward-sloping in booms and 
downward-sloping in recessions. Alternatively, if $q_{g}^{(1)}<q_{b}^{(1)}$ (the short-term interest rate is pro-cyclical), the yield curve must be downward-sloping in booms and upwardsloping in recessions. Note that this result follows from simple manipulation of the prices of contingent claims, and thus it follows whether or not there are incomplete markets for idiosyncratic risks (as long as there are complete markets for aggregate risk).

However, when there is no idiosyncratic risk (or when this risk is fully insured), so that there is a representative agent, we also know that $q_{g}^{(1)}>q_{b}^{(1)}$ must hold given any mean-reverting process, so in a complete-markets model the yield curve must be upward-sloping in booms and downward-sloping in recessions. In this model, in contrast, we can obtain the reverse result, since $q_{g}^{(1)}<q_{b}^{(1)}$ is possible: as the last section showed, it is the expected growth in consumption of the rich agent that matters for bond pricing, and not expected aggregate consumption growth. Thus, if rich agents have higher expected consumption growth in booms than in recessions, the short-term interest rate will be pro-cyclical in this model, and the yield curve will slope upward in recessions and downward in booms.

The magnitude of the slope is also possible to examine: it depends on the relative magnitudes of $Q_{z g}$ and $Q_{z b}$. These, in turn, depend on any possible (a)symmetry in the cycle, in the case without idiosyncratic risks, and on details of the consumption process of the rich, in the case of incomplete markets studied here. Figures 2 and 3 depict yield curves, assuming that $Q_{g g}=Q_{b b}=0.6$, with horizons up to 10 periods. Three curves are drawn for different combinations of $Q_{g b}$ and $Q_{b g}$, thus allowing both the cases of pro-cyclical and counter-cyclical short-term rates.

Figure 4 depicts the yield curves for symmetric $\left(Q_{g g}=Q_{b b}=0.6, Q_{g b}=0.38\right.$, and $\left.Q_{b g}=0.35\right)$ and asymmetric $\left(Q_{g g}=0.6, Q_{b b}=0.3, Q_{g b}=0.38\right.$, and $\left.Q_{b g}=0.65\right)$ business cycles. Here, we keep $Q_{g g}$ and $Q_{g b}$ the same and change $Q_{b b}$ and $Q_{b g}$ holding $Q_{b g}+Q_{b b}$ constant.

We also note that there are individual endowment processes for which the yield curve is non-monotonic. Figure 5 illustrates. 


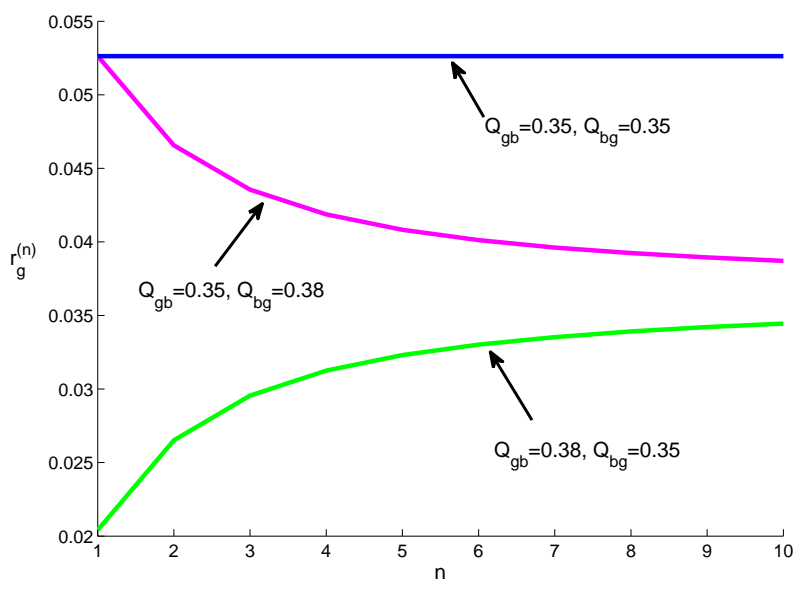

Figure 2: Yield curves in booms: $r_{g}^{(n)}$

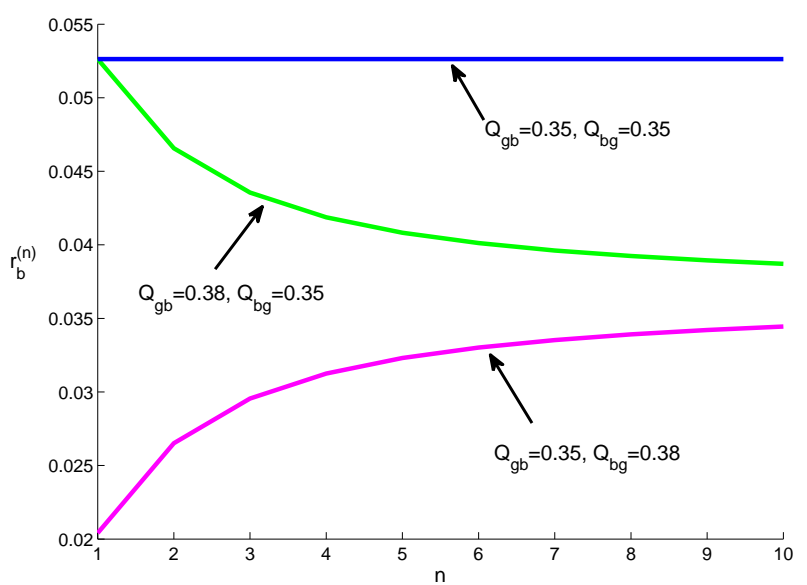

Figure 3: Yield curves in recessions: $r_{b}^{(n)}$

\subsubsection{The equity risk premium}

If there is an asset that provides $Y_{g}$ when the next-period aggregate state is good and $Y_{b}$ when the next-period aggregate state is bad, then its price is

$$
P_{z}=\sum_{z^{\prime}=g, b} Y_{z^{\prime}} Q_{z z^{\prime}}=\beta \sum_{z^{\prime}=g, b} Y_{z^{\prime}} \phi_{z z^{\prime}} m_{z z^{\prime}}=E\left[Y_{z^{\prime}} m_{z z^{\prime}}\right]
$$




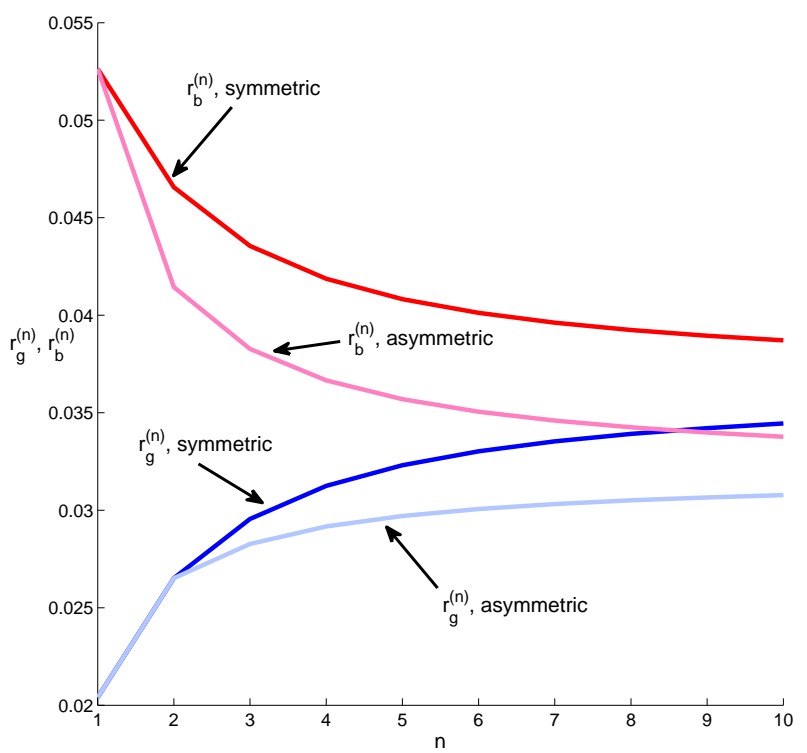

Figure 4: $r_{g}^{(n)}$ and $r_{b}^{(n)}$ for symmetric and asymmetric business cycles

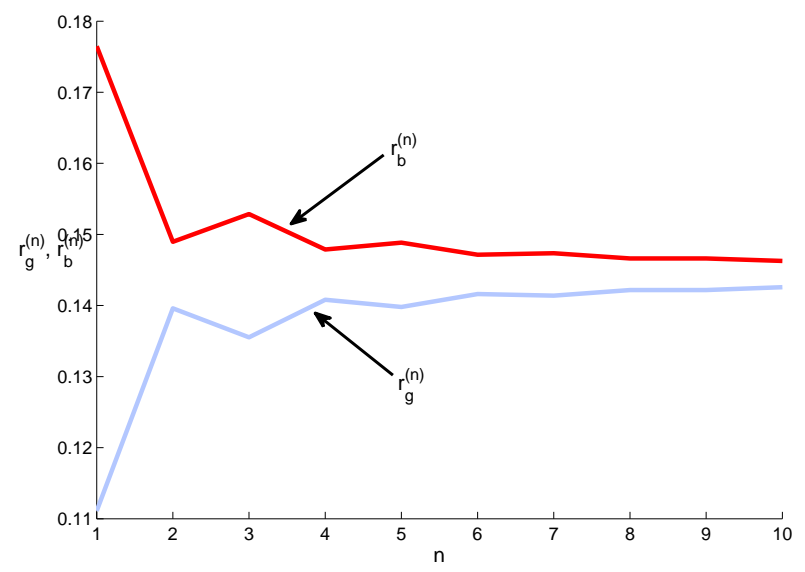

Figure 5: $r_{g}^{(n)}$ and $r_{b}^{(n)}$ for $Q_{g g}=0.1, Q_{b b}=0.15, Q_{g b}=0.8$, and $Q_{b g}=0.7$

The ex-post (gross) return is $R_{z z^{\prime}} \equiv Y_{z^{\prime}} / P_{z}$. Therefore,

$$
1=E\left[R_{z z^{\prime}} m_{z z^{\prime}}\right]
$$

holds. This implies that $m_{z z^{\prime}}$ is the pricing kernel in this economy. 
Define the risk premium as $R_{z z^{\prime}}^{e} \equiv R_{z z^{\prime}}-R_{z}^{f}$. In the following, we analyze the risk premium in this economy using a method similar to that used in Krusell and Smith (1997), thus exploiting the two-state nature of the endowment process for simple analytics.

From (11) and (16),

$$
E\left[R_{z z^{\prime}}^{e} m_{z z^{\prime}}\right]=0
$$

Since

$$
E\left[R_{z z^{\prime}}^{e} m_{z z^{\prime}}\right]=E\left[R_{z z^{\prime}}^{e}\right] E\left[m_{z z^{\prime}}\right]+\operatorname{Cov}\left(R_{z z^{\prime}}^{e}, m_{z z^{\prime}}\right)
$$

the following holds.

$$
E\left[R_{z z^{\prime}}^{e}\right] E\left[m_{z z^{\prime}}\right]=-\operatorname{Cov}\left(R_{z z^{\prime}}^{e}, m_{z z^{\prime}}\right)
$$

Now we are able to state and prove the following proposition.

Proposition 2 Suppose that $Y_{g}>Y_{b}$. The expected value of risk premium, $E\left[R_{z z^{\prime}}^{e}\right]$, is positive if and only if $\pi_{h h \mid z g}-\pi_{h h \mid z b}>0$.

Proof: See Appendix.

Again, the persistence of the endowment process for the rich consumer, $\pi_{h h \mid z z^{\prime}}$, plays a key role. Now, let us investigate how our model can be helpful in addressing the equity premium puzzle. Suppose that $\pi_{h h \mid z g}-\pi_{h h \mid z b}>0$. Following Krusell and Smith (1997), now we show that the Sharpe ratio for an asset with $Y_{g}>Y_{b}$ is exactly equal to the market price of risk. From (17),

$$
E\left[R_{z z^{\prime}}^{e}\right] E\left[m_{z z^{\prime}}\right]=-\rho\left(R_{z z^{\prime}}^{e}, m_{z z^{\prime}}\right) \sigma\left[R_{z z^{\prime}}^{e}\right] \sigma\left[m_{z z^{\prime}}\right]
$$

Here, $\rho(A, B)$ denotes the correlation coefficient between random variables $A$ and $B$ and $\sigma[A]$ denotes the standard deviation of $A$ (both conditional on $z$ ). Since

$$
\rho\left(R_{z z^{\prime}}^{e}, m_{z z^{\prime}}\right)=-\rho\left(Y_{z^{\prime}}, \pi_{h h \mid z z^{\prime}}\right)=-1
$$

we find

$$
\frac{E\left[R_{z z^{\prime}}^{e}\right]}{\sigma\left[R_{z z^{\prime}}^{e}\right]}=\frac{\sigma\left[m_{z z^{\prime}}\right]}{E\left[m_{z z^{\prime}}\right]}
$$


The left-hand side is the Sharpe ratio, and the right-hand side is the market price of risk.

From the definition of $m_{z z^{\prime}}$, the market price of risk can be calculated as

$$
\frac{\sigma\left[m_{z z^{\prime}}\right]}{E\left[m_{z z^{\prime}}\right]}=\frac{(\omega-1)\left(\pi_{h h \mid z g}-\pi_{h h \mid z b}\right) \sqrt{\phi_{z g}\left(1-\phi_{z g}\right)}}{\omega-(\omega-1) E\left[\pi_{h h \mid z z^{\prime}}\right]} .
$$

Note that From (9),

$$
m_{z b}-m_{z g}=\beta(\omega-1)\left(\pi_{h h \mid z g}-\pi_{h h \mid z b}\right)
$$

holds. Using this and (12), (18) can also be expressed as

$$
\frac{\sigma\left[m_{z z^{\prime}}\right]}{E\left[m_{z z^{\prime}}\right]}=\frac{\left(m_{z b}-m_{z g}\right) \sqrt{\phi_{z g}\left(1-\phi_{z g}\right)}}{q_{z}} .
$$

\subsection{Can the incomplete-markets model generate plausible as- set prices?}

In this section, we evaluate asset prices in this model quantitatively. Clearly, our borrowing constraint is too tight compared to the reality - in reality, people do borrow and lend. The purpose of this section is thus to obtain a quantitative assessment of the "upper bound" that can be achieved with the incomplete-markets model.

In Section 3.3.2, we show that by judicious choice of the process for idiosyncratic risk, our model with tight (binding) borrowing constraints can, in fact, reproduce any pricing kernel and, hence, any set of asset prices. This result requires that the pricing kernel satisfy a restriction identical to the one in Constantinides and Duffie (1996), who obtain an analogous result in a different environment (one in which idiosyncratic shocks to income are permanent). The required process for idiosyncratic risk, however, need not be quantitatively reasonable. We begin, therefore, in Section 3.3.1 with a quantitative model in the spirit of Mehra and Prescott (1985) in which we calibrate the process for idiosyncratic risk to match observed data. For this quantitatively reasonable model, we show that our model with tight borrowing constraints can in fact come close to matching the first and second moments of returns on riskfree bonds and on equity in U.S. data. 


\subsubsection{A quantitative investigation}

In this section, we show that our model can reproduce U.S. asset pricing behavior when the process for idiosyncratic shocks is calibrated in a quantitatively reasonable way. Following Mehra and Prescott (1985), we extend the model with aggregate uncertainty developed in Section 3.1 to allow the aggregate endowment to grow stochastically. In particular, letting $y_{t}$ be the aggregate endowment in period $t$, we assume that $y_{t}=\gamma_{t} y_{t-1}$, where $\gamma_{t} \in\left[\gamma^{g}, \gamma^{b}\right]$ is the growth rate of the aggregate endowment. The growth rate $\gamma_{t}$ depends on the aggregate state $z_{t}: \gamma_{t}=\gamma^{z_{t}}$.

We assume that fraction $1-\alpha$ of the aggregate endowment is the dividend of a Lucas tree and that fraction $\alpha$ is "labor" income. Each consumer is endowed with one tree; each tree, then, yields a dividend $(1-\alpha) y_{t}$ in period $t$. An individual consumer's labor income is subject to idiosyncratic shocks. In particular, in any period fraction $\chi$ of consumers receives a "high" multiple, $\epsilon_{h}$, of the aggregate labor endowment and fraction $1-\chi$ of consumers receives a "low" multiple, $\epsilon_{l}<\epsilon_{h}$, of the aggregate labor endowment, where we impose the adding-up restriction that $\chi \epsilon_{h}+(1-\chi) \epsilon_{l}=1{ }^{6}$ With tight borrowing constraints, there is no trade in assets: in any period each consumer simply consumes his total endowment $\left(\alpha \epsilon_{t}+1-\alpha\right) y_{t}$.

We impose a set of constraints on the transition probabilities $\pi_{s s^{\prime} \mid z z^{\prime}}$ to ensure that the fraction of consumers receiving the shock $\epsilon_{h}$ in any period is indeed equal to $\chi$ : in particular, for all pairs $\left(z, z^{\prime}\right)$, we require

$$
\chi \pi_{h h \mid z z^{\prime}}+(1-\chi) \pi_{l h \mid z z^{\prime}}=\chi .
$$

Adapting the arguments from Section 3.2, it is straightforward to show that with tight borrowing constraints the high-endowment consumer prices the contingent claims, in which case the pricing kernel is:

$$
m_{z z^{\prime}}=\beta\left(\gamma^{z^{\prime}}\right)^{-\sigma}\left[\phi_{h h \mid z z^{\prime}}+\left(1-\phi_{h h \mid z z^{\prime}}\right)\left(\frac{\alpha \epsilon_{h}+1-\alpha}{\alpha \epsilon_{l}+1-\alpha}\right)^{\sigma}\right] .
$$

\footnotetext{
${ }^{6}$ Note that the interpretation of $\epsilon$ in this section differs slightly from its interpretation in Section 3.1 ; here, it is a multiple of the aggregate labor endowment, whereas there it is the individual labor endowment itself.
} 
In the absence of growth $\left(\gamma^{g}=\gamma^{b}=1\right)$, and setting $\omega=\left(\frac{\alpha \epsilon_{h}+1-\alpha}{\alpha \epsilon_{l}+1-\alpha}\right)^{\sigma}$, this expression is identical to the corresponding expression in Section 3.2 for the pricing kernel. ${ }^{7}$ The pricing kernel can be used exactly as in Mehra and Prescott (1985) to price any assets whose payoffs depend on realizations of the aggregate state. In particular, we compute below returns on a riskless bond and on equity (i.e., a claim to the dividend of the tree).

We assume that a period corresponds to one year. For purposes of comparison, we calibrate the growth rate process exactly as in Mehra and Prescott (1985). Specifically, this process is chosen to match the mean, standard deviation, and first-order autocorrelation of the growth rate of U.S. per capita consumption over the time period 1889-1978, yielding $\gamma^{g}=1.054, \gamma^{b}=0.982$, and $\pi_{g g}=\pi_{b b}=0.43$. We set $\chi$, the fraction of consumers receiving the high labor endowment, equal to 0.2 and we choose the ratio $\epsilon_{h} / \epsilon_{l}$ so that the share of labor income (earnings) received by high-endowment consumers is 0.6, consistent with the findings of Rodríguez et al (2002), who report facts about U.S. economic inequality using the Survey of Consumer Finances and the Panel Survey of Income Dynamics.

Rodríguez et al (2002) also find that the probability that a household remains in the top $20 \%$ of the distribution of labor earnings five years hence is 0.68 . Since $0.925^{5} \approx 0.68$, we infer that that the probability of remaining in the top $20 \%$ one year hence is 0.925 . We interpret this number as an average across business cycles. To calibrate the transition probabilities for the idiosyncratic labor-income shock, however, we need to know how these transition probabilities vary with the aggregate state. In the absence of more detailed data about transitions into and out of the top 20\%, we simply assume that a consumer is more likely to remain in the top $20 \%$ when the economy is transiting to a good state than when it is transiting to a bad state and set (arbitrarily) $\pi_{h h \mid z g}=0.975$ and $\pi_{h h \mid z b}=0.875$ for $z=g, b{ }^{8}$ This choice satisfies the restriction in Proposition 2 ensuring that the equity risk premium in positive.

\footnotetext{
${ }^{7}$ See, in particular, equation (9).

${ }^{8}$ Because the transition probability matrix for the aggregate state is symmetric, the "average" probability of remaining is the top $20 \%$ is the average of $\pi_{h h \mid z g}$ and $\pi_{h h \mid z b}$, or 0.925 .
} 
Recall that our purpose here is simply to investigate whether a plausible process for idiosyncratic risk can generate quantitatively reasonable asset prices in our model.

Consistent with U.S. aggregate data, we set labor's share, $\alpha$, equal to 0.64. We set risk aversion $\sigma$, equal to 2 and we choose the discount factor, $\beta$, to match the risk-free rate in U.S. data. Table 1 reports unconditional moments of asset prices both in the model and in U.S. data, as reported in Mehra and Prescott (1985) using annual data for 1889-1978.

Table 1

\begin{tabular}{l|rr} 
& Data & Model \\
\hline Mean riskfree rate & $0.80 \%$ & $0.80 \%$ \\
Mean equity premium & $6.18 \%$ & $4.86 \%$ \\
Std. dev. riskfree rate & $5.67 \%$ & $7.05 \%$ \\
Std. dev. equity premium & $16.67 \%$ & $9.77 \%$ \\
Sharpe ratio & 0.37 & 0.50 \\
\hline
\end{tabular}

The table shows that the calibrated model is fairly successful in reproducing the first and second moments of the returns on riskless bonds and equity in U.S. data. A caveat is that the calibrated discount factor is 0.332 , which is low compared to measurements of discount factors typically obtained through surveys and experiments.

\subsubsection{Connections to some known results in the literature}

Recently, Krueger and Lustig (2007) demonstrated that, in certain contexts, the equity premium in an incomplete-markets model is identical to that in the complete-markets model. This finding seems to be at odds with our earlier results - that market incompleteness can have a large effect on the risk premium. However, Krueger and Lustig's result applies in our economy as well, provided we make assumptions in line with the assumptions they make, and below, we demonstrate their irrelevance result in the context of our model. We have to somewhat modify our model to allow the Krueger-Lustig special case. We derive closed-form solutions for asset prices in our modified model, and we also slightly relax one of their assumptions. The assumptions needed for the irrelevance result, even in their slightly relaxed form, are, however, rather restrictive. 
A different kind of result is obtained in Constantinides and Duffie (1996). They show that given an aggregate consumption process and given specific preference parameters, it is (under a mild condition) possible to find an individual endowment process that is consistent with the aggregate endowment process and that matches any asset-pricing facts. Thus, in contrast to Krueger and Lustig's argument that incomplete-markets settings are incapable (under some conditions) of explaining asset

prices, Constantinides and Duffie instead point to the model's capability of matching any asset prices. We comment on Constantinides and Duffie's results by providing a result to the same effect: the incomplete-markets model is quite capable in principle many asset-price characteristics. This result, however, is perhaps only interesting in terms of how our findings compare to the existing literature, since we argue above that the incomplete-markets model does not succeed quantitatively: the endowment process required to match prices is not realistic.

\section{Krueger and Lustig (2007):}

In order to accommodate Krueger and Lustig's assumptions, we will modify our model first by allowing for the values of $\epsilon_{h}$ and $\epsilon_{\ell}$ to vary across the aggregate states. With a slight abuse of notation, let us denote the value of $\epsilon_{s}$ when the aggregate state is $z$ by $\epsilon_{s z}$. The first assumption by Krueger and Lustig is that the individual endowment varies proportionally with the aggregate states:

$$
\frac{\epsilon_{h g}}{\epsilon_{h b}}=\frac{\epsilon_{\ell g}}{\epsilon_{\ell b}} .
$$

We let this ratio be denoted $\xi>1$. This implies that $\epsilon_{h g} / \epsilon_{\ell g}=\epsilon_{h b} / \epsilon_{\ell b}$. To be consistent with the previous notation, we let $\left(\epsilon_{h g} / \epsilon_{\ell g}\right)^{\sigma}=\left(\epsilon_{h b} / \epsilon_{\ell b}\right)^{\sigma}=\omega$.

The second important assumption employed by Krueger and Lustig is that $\pi_{s s^{\prime} \mid z z^{\prime}}$ is independent of $z$ and $z^{\prime}$ (notice, already at this point, that the key requirement in our quantitative section, i.e., a large positive value of $\pi_{h h \mid z g}-\pi_{h h \mid z b}$, is ruled out). We denote this aggregate-state-independent probability $\pi_{s s^{\prime}}$. This assumption implies that there exists a stationary distribution over individual states. The first assumption, in turn, then implies that $z$ only affects the aggregate endowment: all endowments are 
scaled up and down as the economy experiences a boom and a recession. We normalize the aggregate endowment in $z=b$ to 1 , so that the aggregate endowment when $z=g$ is $\xi$. Below we consider such a stationary situation.

The consumer's first-order conditions for this economy implies

$$
\frac{Q_{z z^{\prime}}}{\beta \phi_{z z^{\prime}}}-\frac{\lambda_{s z}^{z^{\prime}}}{\beta \phi_{z z^{\prime}} \epsilon_{s z}^{-\sigma}}=\pi_{s h}\left(\frac{\epsilon_{s z}}{\epsilon_{h z^{\prime}}}\right)^{\sigma}+\left(1-\pi_{s \ell}\right)\left(\frac{\epsilon_{s z}}{\epsilon_{\ell z^{\prime}}}\right)^{\sigma}
$$

As for our baseline model, it is straightforward to show that the borrowing constraint is binding for $s=\ell$ consumers and that $Q_{z z^{\prime}}$ is determined by the first-order condition of the $s=h$ consumers.

With our assumptions on the endowment, the Arrow-security prices therefore become

$$
\begin{gathered}
Q_{g g}=\beta \phi_{g g}\left[\pi_{h h}+\left(1-\pi_{h h}\right) \omega\right], \\
Q_{b b}=\beta \phi_{b b}\left[\pi_{h h}+\left(1-\pi_{h h}\right) \omega\right], \\
Q_{g b}=\beta \phi_{g b} \xi^{\sigma}\left[\pi_{h h}+\left(1-\pi_{h h}\right) \omega\right],
\end{gathered}
$$

and

$$
Q_{b g}=\beta \phi_{b g} \xi^{-\sigma}\left[\pi_{h h}+\left(1-\pi_{h h}\right) \omega\right]
$$

From here on, define $\theta \equiv\left[\pi_{h h}+\left(1-\pi_{h h}\right) \omega\right]$.

Suppose that the current state is $z=g$. The (gross) bond return is

$$
R_{g}^{f}=\frac{1}{\sum_{z^{\prime}=g, b} Q_{g z^{\prime}}}=\frac{1}{\beta \theta\left(\phi_{g g}+\phi_{g b} \xi^{\sigma}\right)}
$$

and the (gross) expected return of a risky asset which provides $Y_{g}$ when $z^{\prime}=g$ and $Y_{b}$ when $z^{\prime}=b$ is

$$
E\left[R_{g z^{\prime}}^{e}\right]=\sum_{z^{\prime}=g, b} \phi_{g z^{\prime}} \frac{Y_{z^{\prime}}}{P_{g}}=\frac{\sum_{z^{\prime}=g, b} \phi_{g z^{\prime}} Y_{z^{\prime}}}{\sum_{z^{\prime}=g, b} Q_{g z^{\prime}} Y_{z^{\prime}}}=\frac{\sum_{z^{\prime}=g, b} \phi_{g z^{\prime}} Y_{z^{\prime}}}{\beta \theta\left(\phi_{g g} Y_{g}+\phi_{g b} \xi \sigma Y_{b}\right)},
$$

where $P_{z}$ is the price of this asset when the aggregate state is $z$. From these, the multiplicative risk premium (equity premium) can be calculated as

$$
\frac{E\left[R_{g z^{\prime}}^{e}\right]}{R_{g}^{f}}=\frac{\left(\phi_{g g}+\phi_{g b} \xi^{\sigma}\right) \sum_{z^{\prime}=g, b} \phi_{g z^{\prime}} Y_{z^{\prime}}}{\left(\phi_{g g} Y_{g}+\phi_{g b} \xi^{\sigma} Y_{b}\right)}
$$


An important fact here is that $\theta$ cancels out. All the parameters that appear on the right-hand side are parameters determining aggregates.

When markets are complete in this economy, the representative agent consumes 1 when $z=b$ and $\xi$ when $z=g$. The Lucas asset pricing formula implies that

$$
\begin{gathered}
Q_{g g}=\beta \phi_{g g}, \\
Q_{b b}=\beta \phi_{b b}, \\
Q_{g b}=\beta \phi_{g b} \xi^{\sigma},
\end{gathered}
$$

and

$$
Q_{b g}=\beta \phi_{b b} \xi^{-\sigma}
$$

Note that these differ from the incomplete-markets security prices only by the constant factor $\theta$. Considering $z=g$, the gross bond return is:

$$
R_{g}^{f}=\frac{1}{\sum_{z^{\prime}=g, b} Q_{g z^{\prime}}}=\frac{1}{\beta\left(\phi_{g g}+\phi_{g b} \xi^{\sigma}\right)} .
$$

The gross return on the risky asset is

$$
E\left[R_{g z^{\prime}}^{e}\right]=\sum_{z^{\prime}=g, b} \phi_{g z^{\prime}} \frac{Y_{z^{\prime}}}{P_{g}}=\frac{\sum_{z^{\prime}=g, b} \phi_{g z^{\prime}} Y_{z^{\prime}}}{\sum_{z^{\prime}=g, b} Q_{g z^{\prime}} Y_{z^{\prime}}}=\frac{\sum_{z^{\prime}=g, b} \phi_{g z^{\prime}} Y_{z^{\prime}}}{\beta\left(\phi_{g g} Y_{g}+\phi_{g b} \xi^{\sigma} Y_{b}\right)} .
$$

Therefore, the multiplicative risk premium is

$$
\frac{E\left[R_{g z^{\prime}}^{e}\right]}{R_{g}^{f}}=\frac{\left(\phi_{g g}+\phi_{g b} \xi^{\sigma}\right) \sum_{z^{\prime}=g, b} \phi_{g z^{\prime}} Y_{z^{\prime}}}{\left(\phi_{g g} Y_{g}+\phi_{g b} \xi^{\sigma} Y_{b}\right)}
$$

which is the same as in the incomplete-markets case. Therefore, we established that the risk premium is not affected by the market incompleteness, although the level of the risk-free rate is affected. The case of $z=b$ can be established similarly.

What is important in this derivation is that $\theta$ cancels out when we calculate the risk premium. For this to occur, the value $\pi_{h h}+\left(1-\pi_{h h}\right) \omega$ has to be common across different values of $z^{\prime}$. Incomplete markets matter for the risk premium in the KruegerLustig version of the model when, for example, $\pi_{h h \mid z g}$ is different from $\pi_{h h \mid z b}$. This 
observation is closely related to our Proposition 2: $\pi_{h h \mid z z^{\prime}}$ is a key parameter for asset pricing in the incomplete-markets model. ${ }^{9}$

In the following, we relax the above assumptions. First, we relax the condition (21). When the $\pi_{s s^{\prime}} \mathrm{S}$ are independent of $z$ and $z^{\prime}$, we can derive a necessary and sufficient condition for the multiplicative equity premium to be the same across the complete-markets model and our incomplete-markets model. To be precise, first note that when the $\pi_{s s^{\prime}}$ s are independent of $z$, there is a stationary distribution over the individual states. In fact, assuming that the total population is one, the fraction of the consumers with state $s$ (denoted $\chi_{s}$ ) is completely pinned down by the $\pi_{s s^{\prime}} \mathrm{S}$. For example, $\chi_{h}$ is

$$
\chi_{h}=\frac{\pi_{\ell h}}{1-\pi_{h h}+\pi_{\ell h}} .
$$

For a stationary state, the following result is attained.

Proposition 3 Suppose that $\pi_{s s^{\prime} \mid z z^{\prime}}$ is independent of $z$ and $z^{\prime}$. Then, the multiplicative risk premium for any asset whose return depends only on the aggregate state in the stationary equilibrium is the same across the complete-markets model and our incomplete-markets model if and only if the condition

$$
\frac{\pi_{h h} \epsilon_{h g}^{-\sigma}+\left(1-\pi_{h h}\right) \epsilon_{\ell g}^{-\sigma}}{\pi_{h h} \epsilon_{h b}^{-\sigma}+\left(1-\pi_{h h}\right) \epsilon_{\ell b}^{-\sigma}}=\frac{\left(\pi_{\ell h} \epsilon_{h g}+\left(1-\pi_{h h}\right) \epsilon_{\ell g}\right)^{-\sigma}}{\left(\pi_{\ell h} \epsilon_{h b}+\left(1-\pi_{h h}\right) \epsilon_{\ell b}\right)^{-\sigma}}
$$

holds.

Proof: See Appendix.

Clearly, when the condition (21) is satisfied, (23) is automatically satisfied. The condition (23) highlights the possibility that the irrelevance result would hold outside Krueger and Lustig's assumption: even when (21) is not satisfied, if the $\pi_{s s^{\prime}}$ s satisfy the condition (23), the irrelevance result still holds.

Second, we relax the independence assumptions on the transition probabilities. When the $\pi_{s s^{\prime}}$ S are not independent of $z$ and $z^{\prime}$, in general the distribution of the

\footnotetext{
${ }^{9}$ In Proposition 2, the risk premium is zero when $\pi_{h h \mid z g}=\pi_{h h \mid z b}$. Here, the risk premium can still be positive when $\pi_{h h \mid z g}=\pi_{h h \mid z b}$, since the $\epsilon_{s}$ s are different across different $z^{\prime}$ s.
} 
idiosyncratic states moves around over time. In this case, an irrelevance result is difficult to come by, since aggregate consumption is affected not only by the $\pi_{s s^{\prime}} \mathrm{S}$ and $\epsilon_{s} \mathrm{~s}$ but also by the fractions $\chi_{s}$, which move over time (note that the prices in the incomplete-markets model are not affected by the $\chi_{s} \mathrm{~s}$ ). For $\chi_{s}$ to be constant (or just a function of $z$ ), we need some restrictions on the transition probabilities $\pi_{s s^{\prime} \mid z z^{\prime}} \mathrm{S}$. In particular, letting $\chi_{s z}$ denote the fraction of type- $s$ consumers in state $z$,

$$
\chi_{h z} \pi_{h h \mid z z^{\prime}}+\left(1-\chi_{h z}\right) \pi_{\ell h \mid z z^{\prime}}=\chi_{h z^{\prime}}
$$

has to be satisfied for any $z$ and $z^{\prime}{ }^{10}$ When this condition is satisfied, a necessary and sufficient condition for the irrelevance becomes (by the same logic as above)

$$
\frac{\pi_{h h \mid z g} \epsilon_{h g}^{-\sigma}+\left(1-\pi_{h h \mid z g}\right) \epsilon_{\ell g}^{-\sigma}}{\pi_{h h \mid z b} \epsilon_{h b}^{-\sigma}+\left(1-\pi_{h h \mid z b}\right) \epsilon_{\ell b}^{-\sigma}}=\frac{\left(\chi_{h g} \epsilon_{h g}+\left(1-\chi_{h g}\right) \epsilon_{\ell g}\right)^{-\sigma}}{\left(\chi_{h b} \epsilon_{h b}+\left(1-\chi_{h b}\right) \epsilon_{\ell b}\right)^{-\sigma}}
$$

for $z=g, b$. A notable feature of this condition is that it is possible to break the irrelevance result even when $\epsilon_{s g}=\epsilon_{s b}$ (when $\epsilon_{s g}=\epsilon_{s b},(23)$ is automatically satisfied).

\section{Constantinides and Duffie (1996):}

Constantinides and Duffie (1996) proposed a model where, similarly to ours, the equilibrium outcome is autarky. They show that (with given preference parameters and aggregate endowment process), under some conditions, one can find a individual endowment process for a given process of strictly positive pricing kernels. Intuitively, autarky in the Constantinides and Duffie model obtains since the individual shocks are permanent: when individual shocks do not mean-revert, they cannot be insured against with assets that are contingent only on aggregate states. Our framework yields the following result, which is similar in its conclusion, though very different in its construction, since it relies on binding borrowing constraints and is valid for shocks that mean-revert (in fact recurring permanent shocks cannot be accommodated with the simple finite-state Markov chain we consider).

\footnotetext{
${ }^{10}$ This type of condition is used by Krusell and Smith (1998) to make the unemployment rate a function only of the current aggregate state.
} 
Proposition 4 In the model with aggregate uncertainty developed in Section 3.1, for any preference parameters and any given set of values for $m_{z z^{\prime}} \geq \beta$, all $z$ and $z^{\prime}$, we can find a set of parameters for the individual income process given by the parameters $\pi_{s s^{\prime} \mid z z^{\prime}}$, all $s, s^{\prime}, z$ and $z^{\prime}, \epsilon_{h}$, and $\epsilon_{\ell}$, that generates these $m_{z z^{\prime}}$ values as an equilibrium outcome.

Proof: See Appendix.

This result is different from Constantinides and Duffie's in some respects. Since we do not allow the individual endowment level to depend on the aggregate endowment level, our model cannot condition $m_{z z^{\prime}}$ on the aggregate endowment level. That is, the aggregate endowment process in Proposition 4 may not behave in a realistic manner. This feature can be alleviated if we allow $\epsilon_{s}$ to depend on the aggregate endowment level. Such an assumption would (in principle) make the analysis more complex, since it would no longer be the case that the high-endowment consumer always prices the asset. Another difference is that our lower bound for $m_{z z^{\prime}}$ is $\beta$, while their lower bound for the pricing kernel is $\beta\left(C_{t+1} / C_{t}\right)^{-\sigma}$ (in our notation), where $C_{t}$ is the aggregate endowment at time $t$.

In the following proposition, we allow $\epsilon_{h}$ and $\epsilon_{\ell}$ to vary, and we find a result that is closer to Constantinides and Duffie's. Here, we slightly change the notations to express the dependence on the time and the history clearer.

Proposition 5 Denote the history of the aggregate state $z_{t}$ as $z^{t} \equiv\left\{z_{0}, z_{1}, \ldots, z_{t}\right\}$. Let the preference parameters and the aggregate consumption process, $C_{t}\left(z^{t}\right)$, be given. Suppose that we are given the values of the pricing kernel at each point in history, $m_{t+1}\left(z^{t+1}\right)$. Assume that $m_{t+1}\left(z^{t+1}\right)$ satisfies $m_{t+1}\left(z^{t+1}\right) \geq \beta\left(C_{t+1}\left(z^{t+1}\right) / C_{t}\left(z^{t}\right)\right)^{-\sigma}$ for all $z^{t+1}$ and $z^{t} \subset z^{t+1}$, and $\frac{m_{t+1}\left(z^{t+1}\right)}{\beta\left(C_{t+1}\left(z^{t+1}\right) / C_{t}\left(z^{t}\right)\right)^{-\sigma}}$ is bounded above. Then, for these given values of $m_{t+1}\left(z^{t+1}\right)$, we can find an individual income process given by the idiosyncratic transition probabilities $\pi_{t+1}\left(s_{t+1} \mid s_{t}, z^{t+1}\right)$ (the probability that the endowment $s_{t+1} \in\{h, \ell\}$ realizes at time $t+1$ given $s_{t}$ and $\left.z^{t+1}\right)$, high endowment value $\epsilon_{h t}\left(z^{t}\right)$, low endowment value $\epsilon_{\ell t}\left(z^{t}\right)$, and an initial population of the consumers across 
the endowment values that generates these $m_{t+1}\left(z^{t+1}\right)$ values as an equilibrium outcome.

Proof: See Appendix.

This means that, in terms of generality, our model with variable $\epsilon_{s} \mathrm{~s}$ can perform as well as Constantinides and Duffie's (1996) model in terms of matching asset-pricing facts, when we are given the preference parameters, the aggregate consumption data, and the asset-price data.

\section{More than two individual endowment states}

In this section, we extend the model to incorporate the possibility of more than two possible values of the individual endowment. Most of the results in the two-state case extend to this new environment. The main difference is that now asset prices are not necessarily determined by the richest (highest-endowment) consumers.

\subsection{The economy without aggregate uncertainty}

The next proposition generalizes Proposition 1 to the case where $\epsilon$ takes on $N$ different values $\left\{\epsilon_{1}, \epsilon_{2}, \ldots, \epsilon_{N}\right\}$, with $\epsilon_{1}<\epsilon_{2} \cdots<\epsilon_{N}$, and where the utility function is more general.

Proposition 6 When $\epsilon$ takes on $N$ different values $\left\{\epsilon_{1}, \epsilon_{2}, \ldots, \epsilon_{N}\right\}$ and the consumer has an increasing and strictly concave utility function $u(c)$, the equilibrium bond price can be characterized by:

$$
q \geq q^{*} \equiv \max _{i=2, \ldots, N} M_{i}
$$

where

$$
M_{i} \equiv \beta \sum_{j=1}^{N} \pi_{i j} \frac{u^{\prime}\left(\epsilon_{j}\right)}{u^{\prime}\left(\epsilon_{i}\right)}
$$


The proof is omitted, since its steps are very similar to Proposition 1. Note that the smallest-endowment consumers $\left(\epsilon=\epsilon_{1}\right)$ are excluded from the max in $(24)$, since, as in the previous case, they are always strictly borrowing-constrained. In this case, it may not be the case that the highest-endowment consumers' marginal rates of substitution determine $q^{*}$. If $M_{j}$ is larger with a $j \neq N$, a consumer with the endowment level $j$ is a "pricer" of the bond.

\subsubsection{Comparative statics}

As is shown in the previous analysis, when the endowment takes only two values, $q^{*}$ is decreasing in $\pi_{h h}$. This result can be generalized to the following proposition.

Proposition 7 Consider $\pi_{i j}$ as well as $\hat{\pi}_{i j}$, where, for each $i=2, \ldots, N$, $\hat{\pi}_{i j}$ first-order stochastically dominates $\pi_{i j}$. Then $q^{*}$ is smaller under $\hat{\pi}_{i j}$ than under $\pi_{i j}$.

Proof: See Appendix.

Clearly, the comparative statics with respect to $\beta$ are similar to those of the two-value endowment case. The comparative statics with respect to $\sigma$, when $u(c)=c^{1-\sigma} /(1-\sigma)$, are not as straightforward (it is indeed straightforward if $\arg \max _{i=1, \ldots, N} M_{i}=N$ ). However, it turns out nevertheless that $q^{*}$ is always increasing in $\sigma$.

Proposition $8 q^{*}$ is increasing in $\sigma$.

Proof: See Appendix.

The intuition is that, if a consumer with endowment $i$ prices the bond, there are high weights (either because $\pi$ is large or $\left(\epsilon_{i} / \epsilon_{j}\right)$ is large) on the states where this consumer experiences large consumption drops, and an increase in $\sigma$ further increases the weights on these events.

\subsubsection{Who prices the bond?}

As is stated above, it is not necessarily the case that the highest-endowment consumer determines the bond price. A sufficient condition for this to be guaranteed can, 
however, be stated.

Proposition 9 Suppose that for all $i=2, \ldots, N-1$ and $n=1, \ldots, i-1$,

$$
\sum_{j=1}^{n} \pi_{N j} \geq \sum_{j=1}^{n} \pi_{i j}
$$

holds. Then, $N \in \arg \max _{i=2, \ldots, N} M_{i}$.

Proof: See Appendix.

The intuition behind (25) is that the highest-endowment consumers face the "most risk" of an endowment loss in the near future, thus giving them the strongest incentive to save for precautionary reasons. A special case is that where (25) holds for all $n=1, \ldots, N$. That is, this would mean that in terms of the distribution over the next-period state $s^{\prime},\left\{\pi_{i s^{\prime}}\right\}$ first-order stochastically dominates $\left\{\pi_{N s^{\prime}}\right\}$.

Another special case is a type of "downward-rigid" wages. Let the state $s=1$ be the unemployment state and the other states as the employment states with different level of wages $\epsilon_{s}\left(\epsilon_{1}\right.$ can be interpreted as unemployment income, home production, or the utility from leisure). Suppose that from any employed state $s=2, \ldots, N$, there is an equal probability of becoming unemployed: $\pi_{21}=\pi_{31}=\cdots=\pi_{N 1}$. Also suppose that the wage is "downward-rigid" except at the very top: $\pi_{i j}=0$ for $i=2, \ldots, N-1$ and $j=2, \ldots, i-1$. It can easily be checked that this Markov transition matrix satisfies (25). Thus, in such an economy too the highest-endowment consumer's marginal rates of substitution determine the bond price.

When (25) is not satisfied, the bond price may be determined by the consumers other than the highest-endowment consumers. Consider the following example. Let $N=3$ and the utility functions be given by $u(c)=c^{1-\sigma} /(1-\sigma)$. Now $M_{2}$ and $M_{3}$ are, by definition, given by

$$
M_{2}=\beta\left[\pi_{21}\left(\frac{\epsilon_{2}}{\epsilon_{1}}\right)^{\sigma}+\pi_{22}+\pi_{23}\left(\frac{\epsilon_{2}}{\epsilon_{3}}\right)^{\sigma}\right]
$$

and

$$
M_{3}=\beta\left[\pi_{31}\left(\frac{\epsilon_{3}}{\epsilon_{1}}\right)^{\sigma}+\pi_{32}\left(\frac{\epsilon_{3}}{\epsilon_{2}}\right)^{\sigma}+\pi_{33}\right] .
$$


Here, there would be cases where $M_{2}>M_{3}$. For example, when $\pi_{33}$ is close to 1 and $\pi_{21}$ is close to $1, M_{3}$ is close to 1 and $M_{2}$ is close to $\left(\epsilon_{2} / \epsilon_{1}\right)^{\sigma}>1$; thus, the consumer with the middle endowment level would determine the bond price, since this consumer faces more risk than does the rich consumer. Moreover, $M_{2}$ is increasing in $\epsilon_{2}$ and decreasing in $\epsilon_{3}$, while $M_{3}$ is decreasing in $\epsilon_{2}$ and increasing in $\epsilon_{3}$, and thus the comparative statics with respect to $\epsilon_{2}$ and $\epsilon_{3}$ would depend crucially on whether $M_{2}$ is larger or smaller than $M_{3}$.

\subsubsection{Examples}

This section illustrates two calibrated examples.

\section{Example 1:}

Consider a wage process given by Castañeda, Díaz-Giménez, and Ríos-Rull (2003). To match the earnings and wealth distribution in the United States, they introduce four employment states with different productivity levels, expressed as the effective unit of labor. They also introduce retirement and life cycle effect, but we ignore them here. Their productivity levels are not exactly the same as the income because of the endogenous labor supply and the existence of taxes. We abstract from these factors as well, and we use their calibrated productivity level as the endowment level in our framework. There are four levels of the productivity: $\epsilon_{1}=1.0, \epsilon_{2}=3.15, \epsilon_{3}=9.78$, and $\epsilon_{4}=1061.00$. The transition probabilities are (after adjusting for the retirement probability):

$$
\left(\begin{array}{llll}
\pi_{11} & \pi_{12} & \pi_{13} & \pi_{14} \\
\pi_{21} & \pi_{22} & \pi_{23} & \pi_{24} \\
\pi_{31} & \pi_{32} & \pi_{33} & \pi_{34} \\
\pi_{41} & \pi_{42} & \pi_{43} & \pi_{44}
\end{array}\right)=\left(\begin{array}{llll}
0.98429 & 0.00117 & 0.00399 & 0.00006 \\
0.03140 & 0.96482 & 0.00378 & 0.00000 \\
0.01534 & 0.00440 & 0.98006 & 0.00020 \\
0.10903 & 0.00501 & 0.06249 & 0.82346
\end{array}\right) .
$$

We use $\sigma=1.5$ and $\beta=0.924$, following Castañeda, Díaz-Giménez, and Ríos-Rull (2003). Then, when there is no borrowing/saving, $M_{i}$ can be calculated by

$$
M_{i}=\beta\left(\pi_{i 1}\left(\frac{\epsilon_{1}}{\epsilon_{j}}\right)^{-\sigma}+\pi_{i 2}\left(\frac{\epsilon_{2}}{\epsilon_{j}}\right)^{-\sigma}+\pi_{i 3}\left(\frac{\epsilon_{3}}{\epsilon_{j}}\right)^{-\sigma}+\pi_{i 4}\left(\frac{\epsilon_{4}}{\epsilon_{j}}\right)^{-\sigma}\right) .
$$


From the above calibration, $\left(M_{1}, M_{2}, M_{3}, M_{4}\right)=(0.91,1.05,1.36,3576.38)$. Therefore, the highest-endowment consumer prices the bond in this example.

\section{Example 2:}

Floden and Lindé (2001) estimate the following AR(1) wage process (after controlling for the observable characteristics and measurement errors) from

$$
\log \left(\epsilon_{t+1}\right)=a+\rho \log \left(\epsilon_{t}\right)+\eta_{t+1}
$$

$\eta \sim\left(0, \sigma^{2}\right)$. Floden and Lindé estimate that $\rho=0.9136$ and $\sigma=0.2064$. We use this process as the wage process and approximate this by 4-state Markov process using Tauchen's (1986) method. We set the maximum and minimum of $\log (\epsilon)$ as plus and minus four (unconditional) standard deviation of $\log (\epsilon)$. This leads to $\epsilon_{1}=1.0$, $\epsilon_{2}=3.87, \epsilon_{3}=14.99$, and $\epsilon_{4}=58.02$ and

$$
\left(\begin{array}{llll}
\pi_{11} & \pi_{12} & \pi_{13} & \pi_{14} \\
\pi_{21} & \pi_{22} & \pi_{23} & \pi_{24} \\
\pi_{31} & \pi_{32} & \pi_{33} & \pi_{34} \\
\pi_{41} & \pi_{42} & \pi_{43} & \pi_{44}
\end{array}\right)=\left(\begin{array}{llll}
0.99243 & 0.00757 & 0.00000 & 0.00000 \\
0.00018 & 0.99844 & 0.00137 & 0.00000 \\
0.00000 & 0.00137 & 0.99844 & 0.00018 \\
0.00000 & 0.00000 & 0.00757 & 0.99243
\end{array}\right) .
$$

We maintain the assumption of $\sigma=1.5$ and $\beta=0.924$. From $(26),\left(M_{1}, M_{2}, M_{3}, M_{4}\right)=$ $(0.92,0.92,0.93,0.97)$. Again, the highest-endowment consumer prices the bond. Now the bond price is at a reasonable value. This is because the highest-endowment consumer's probability of "falling" is very small. The conclusion somewhat changes if, for example, we use finer grid points. If we approximate by six-point process with $\epsilon_{1}=1.0, \epsilon_{2}=2.25, \epsilon_{3}=5.08, \epsilon_{4}=11.43, \epsilon_{5}=25.76$, and $\epsilon_{6}=58.02$, the resulting $M$ 's are $\left(M_{1}, M_{2}, M_{3}, M_{4}, M_{5}, M_{6}\right)=(0.83,0.89,0.94,0.99,1.08,1.21)$.

\subsection{The economy with aggregate uncertainty}

Similarly to Proposition 6, it is possible to extend the model with aggregate uncertainty to allow for $N$ different values of $\epsilon \in\left\{\epsilon_{1}, \epsilon_{2}, \ldots, \epsilon_{N}\right\}$, where $\epsilon_{1}<\epsilon_{2} \cdots<\epsilon_{N}$. Again, the utility function can also be generalized to any increasing and strictly concave function 
$u(c)$. In this case, the security price $Q_{z z^{\prime}}$ is, assuming again that it is determined by the lower bound, given by

$$
Q_{z z^{\prime}}=\phi_{z z^{\prime}} \max _{i=2, \ldots, N} M_{i \mid z z^{\prime}}
$$

where

$$
M_{i \mid z z^{\prime}} \equiv \beta \sum_{j=1}^{N} \pi_{i j \mid z z^{\prime}} \frac{u^{\prime}\left(\epsilon_{j}\right)}{u^{\prime}\left(\epsilon_{i}\right)} .
$$

Note that it is possible that $Q_{z z^{\prime}}$ can be based on the marginal rates of substitution of different consumers for different aggregate states $\left(z, z^{\prime}\right)$. Therefore, it is possible, for example, that $q_{z}=\sum_{z^{\prime}} Q_{z z^{\prime}}$ is stable across different $z$ s even though the individual values for $\sum_{z^{\prime}} \phi_{z z^{\prime}} M_{i \mid z z^{\prime}}$ are volatile.

To illustrate this point in more detail, let us consider the following example.

$$
\begin{aligned}
& {\left[\pi_{i j \mid z z^{\prime}}\right]=\left(\begin{array}{lll}
0 & 1 & 0 \\
1 & 0 & 0 \\
0 & 0 & 1
\end{array}\right) \quad \text { for } z=g \text { and } z^{\prime}=g, b,} \\
& {\left[\pi_{i j \mid z z^{\prime}}\right]=\left(\begin{array}{lll}
1 & 0 & 0 \\
0 & 0 & 1 \\
0 & 1 & 0
\end{array}\right) \quad \text { for } z=b \text { and } z^{\prime}=g, b .}
\end{aligned}
$$

Here, when $z=g, \epsilon_{1}$ and $\epsilon_{2}$ switch with each other, and when $z=b, \epsilon_{2}$ and $\epsilon_{3}$ switch with each other. It can readily be verified that

$$
\left(M_{2 \mid g z^{\prime}}, M_{3 \mid g z^{\prime}}\right)=\left(\beta \frac{u^{\prime}\left(\epsilon_{1}\right)}{u^{\prime}\left(\epsilon_{2}\right)}, \beta\right),
$$

and that

$$
\left(M_{2 \mid b z^{\prime}}, M_{3 \mid b z^{\prime}}\right)=\left(\beta \frac{u^{\prime}\left(\epsilon_{3}\right)}{u^{\prime}\left(\epsilon_{2}\right)}, \beta \frac{u^{\prime}\left(\epsilon_{2}\right)}{u^{\prime}\left(\epsilon_{3}\right)}\right) .
$$

Assume that $u^{\prime}\left(\epsilon_{2}\right) / u^{\prime}\left(\epsilon_{3}\right)=u^{\prime}\left(\epsilon_{1}\right) / u^{\prime}\left(\epsilon_{2}\right)=\kappa(>1)$. Then, the bond price would satisfy $q_{z}=\beta \kappa$ and it is independent of $z$, while at the individual level

$$
\left(\sum_{z^{\prime}} \phi_{z z^{\prime}} M_{2 \mid g z^{\prime}}, \sum_{z^{\prime}} \phi_{z z^{\prime}} M_{3 \mid g z^{\prime}}\right)=\left(\beta \frac{u^{\prime}\left(\epsilon_{1}\right)}{u^{\prime}\left(\epsilon_{2}\right)}, \beta\right)
$$

and

$$
\left(\sum_{z^{\prime}} \phi_{z z^{\prime}} M_{2 \mid b z^{\prime}}, \sum_{z^{\prime}} \phi_{z z^{\prime}} M_{3 \mid b z^{\prime}}\right)=\left(\beta \frac{u^{\prime}\left(\epsilon_{3}\right)}{u^{\prime}\left(\epsilon_{2}\right)}, \beta \frac{u^{\prime}\left(\epsilon_{2}\right)}{u^{\prime}\left(\epsilon_{3}\right)}\right)
$$


are different across $z=g, b$. In this example, the individuals with $\epsilon_{1}$ are always borrowing-constrained, $\epsilon_{2}$ individuals are constrained only when $z=b$, and $\epsilon_{3}$ individuals are constrained only when $z=g$. Here, all the individuals are strictly borrowing-constrained at some point in time, while the risk-free rate is stable over time.

\section{Conclusion}

In this paper, we analyzed a variant of the Huggett (1993) model in order to illustrate how asset pricing may depend on asset-market incompleteness: it focuses on the case when direct insurance against idiosyncratic risks is completely unavailable but insurance against aggregate risk is fully available (so that there is, at each point in time, one asset for each aggregate state next period). In so doing, we also extend the basic Huggett model to one with many idiosyncratic states, aggregate uncertainty, and a general utility function. The limitation of our setting is clear - we require the borrowing constraint to be maximally strict, implying an autarkic equilibrium - but this limitation is also a strength in that it allows closed-form solutions. Because we adopt an extreme borrowing constraint, we use our results to set an upper bound on what the Huggett model is capable of generating in terms of asset prices. Our closed-form solutions allow us to conduct comparative statics straightforwardly. For example, we gain an understanding of how asset prices are influenced by the dependence of individual transition probabilities (and hence idiosyncratic risk) on the aggregate state. Here, we draw a connection to the work by Krueger and Lustig (2007) by deriving their main result (under slightly more general assumptions) as a special case. We also derive a result similar to the one in Constantinides and Duffie (1996), of the sort "give me any asset prices and I will find an endowment process in this economy generating those prices", though, unlike them, we do not need to assume that idiosyncratic shocks

are permanent. Such a result, of course, has to be subjected to quantitative scrutiny, and we argue that our model with tight borrowing constraints can indeed generate realistic-looking asset prices when the process for idiosyncratic risk is calibrated in a 
quantitatively reasonable way.

Most of our results are derived in a very simple setting: there are only two states for idiosyncratic risk, subject to a stationary Markov chain, and these states are the same independently of the aggregate state. We also consider simple extensions of this case, the case of having $N$ shock values being particularly interesting, but do not attempt a broad generalization. Generalizations are possible, however, and should be straightforward. We could also consider the case where individual shocks are permanent (as in Constantinides and Duffie's work) and where the support of the shocks is more complex and aggregate-state dependent. Since our equilibrium construction-indeed the main "trick" of the paper - is to set the borrowing constraints on all assets so tightly as to (just) induce autarky as an equilibrium, it is a much more ambitious extension to consider production and, in particular, a means of physically saving/investing. In the latter case, however, similar equilibrium constructions are sometimes possible, as in Krusell and Smith (1997) and Leduc (2002), where a model with only capital is first solved - in a nontrivial manner, involving numerically computed solutions - and where other assets, such as bonds, with maximally strict borrowing constraints are then priced along the same lines as in this paper. 


\section{Appendix}

\section{A Proofs}

Proof of Proposition 2: From (17) and $E\left[m_{z z^{\prime}}\right]=q_{z}>0, E\left[R_{z z^{\prime}}^{e}\right]$ is positive if and only if $\operatorname{Cov}\left(R_{z z^{\prime}}^{e}, m_{z z^{\prime}}\right)$ is negative. From the definitions of $R_{z z^{\prime}}^{e}, R_{z z^{\prime}}$, and $m_{z z^{\prime}}, \operatorname{Cov}\left(R_{z z^{\prime}}^{e}, m_{z z^{\prime}}\right)$ is negative if and only if $\operatorname{Cov}\left(Y_{z^{\prime}}, \pi_{h h \mid z z^{\prime}}\right)$ is positive.

Proof of Proposition 3: From the definitions of the risk-free rate and the expected return on the risky asset, the multiplicative risk premium is

$$
\frac{E\left[R_{z z^{\prime}}^{e}\right]}{R_{z}^{f}}=\frac{\left(\sum_{z^{\prime}=g, b} Q_{z z^{\prime}}\right)\left(\sum_{z^{\prime}=g, b} \phi_{z z^{\prime}} Y_{z^{\prime}}\right)}{\sum_{z^{\prime}=g, b} Q_{z z^{\prime}} Y_{z^{\prime}}} .
$$

Denote the Arrow security price in the complete-markets economy by $Q_{z z^{\prime}}^{c}$ and the Arrow security price in the incomplete-markets economy as $Q_{z z^{\prime}}^{i}$. Clearly, for $E\left[R_{z z^{\prime}}^{e}\right] / R_{z}^{f}$ to be the same for both economies (and for any $Y_{z^{\prime}}$ ), there has to exist a number $\theta_{z}>0$ that is independent of $z^{\prime}$ and satisfy $Q_{z z^{\prime}}^{i}=\theta_{z} Q_{z z^{\prime}}^{c}$ (and if this is the case, then $\theta_{z}$ cancels out and the equivalence holds). Thus, a necessary and sufficient condition for irrelevance is

$$
\frac{Q_{z g}^{i}}{Q_{z b}^{i}}=\frac{Q_{z g}^{c}}{Q_{z b}^{c}}
$$

for $z=g, b$. The Arrow security prices are determined by

$$
Q_{z z^{\prime}}^{i}=\beta \phi_{z z^{\prime}}\left[\pi_{h h}\left(\frac{\epsilon_{h z^{\prime}}}{\epsilon_{h z}}\right)^{-\sigma}+\pi_{h \ell}\left(\frac{\epsilon_{\ell z^{\prime}}}{\epsilon_{h z}}\right)^{-\sigma}\right]
$$

and

$$
Q_{z z^{\prime}}^{c}=\beta \phi_{z z^{\prime}}\left(\frac{C_{z^{\prime}}}{C_{z}}\right)^{-\sigma}
$$

where aggregate consumption $C_{z}$ is

$$
C_{z}=\chi_{h} \epsilon_{h z}+\chi_{\ell} \epsilon_{\ell z}=\frac{\pi_{\ell h} \epsilon_{h z}+\left(1-\pi_{h h}\right) \epsilon_{\ell z}}{1-\pi_{h h}+\pi_{\ell h}},
$$

where the second equality uses (22). Therefore, (27) becomes

$$
\frac{\pi_{h h}\left(\frac{\epsilon_{h g}}{\epsilon_{h z}}\right)^{-\sigma}+\pi_{h \ell}\left(\frac{\epsilon_{\ell g}}{\epsilon_{h z}}\right)^{-\sigma}}{\pi_{h h}\left(\frac{\epsilon_{h b}}{\epsilon_{h z}}\right)^{-\sigma}+\pi_{h \ell}\left(\frac{\epsilon_{\ell b}}{\epsilon_{h z}}\right)^{-\sigma}}=\frac{\left(\frac{\pi_{\ell h} \epsilon_{h g}+\left(1-\pi_{h h}\right) \epsilon_{\ell g}}{\pi_{\ell h} \epsilon_{h z}+\left(1-\pi_{h h}\right) \epsilon_{\ell z}}\right)^{-\sigma}}{\left(\frac{\pi_{\ell h} \epsilon_{h b}+\left(1-\pi_{h h}\right) \epsilon_{\ell b}}{\pi_{\ell h} \epsilon_{h z}+\left(1-\pi_{h h}\right) \epsilon_{\ell z}}\right)^{-\sigma}},
$$


which is equivalent to (23). Note that (23) does not depend on $z$ (all the terms that depend on $z$ cancel out).

Proof of Proposition 4: From (9), for any $m_{z z^{\prime}} \in[\beta, \beta \omega]$, we can find a $\pi_{h h \mid z z^{\prime}} \in[0,1]$ value that generates this value of $m_{z z^{\prime}}$. The upper bound can be made arbitrarily large by making $\epsilon_{h} / \epsilon_{\ell}$ large.

Proof of Proposition 5: The first-order conditions in the case of varying $\epsilon_{h}$ and $\epsilon_{h}$ are (denoting $z=z_{t}$ and $z^{\prime}=z_{t+1}$ )

$\frac{Q_{t+1}\left(z^{t+1}\right)}{\beta \phi_{z z^{\prime}}}-\frac{\lambda_{h, t+1}\left(z^{t+1}\right)}{\beta \phi_{z z^{\prime}} \epsilon_{h t}\left(z^{t}\right)^{-\sigma}}=\pi_{t+1}\left(h \mid h, z^{t+1}\right)\left(\frac{\epsilon_{h, t+1}\left(z^{t+1}\right)}{\epsilon_{h t}\left(z^{t}\right)}\right)^{-\sigma}+\left(1-\pi_{t+1}\left(h \mid h, z^{t+1}\right)\right)\left(\frac{\epsilon_{\ell, t+1}\left(z^{t+1}\right)}{\epsilon_{h t}\left(z^{t}\right)}\right)^{-\sigma}$

and

$\frac{Q_{t+1}\left(z^{t+1}\right)}{\beta \phi_{z z^{\prime}}}-\frac{\lambda_{\ell, t+1}\left(z^{t+1}\right)}{\beta \phi_{z z^{\prime}} \epsilon_{\ell t}\left(z^{t}\right)^{-\sigma}}=\pi_{t+1}\left(h \mid \ell, z^{t+1}\right)\left(\frac{\epsilon_{h, t+1}\left(z^{t+1}\right)}{\epsilon_{\ell t}\left(z^{t}\right)}\right)^{-\sigma}+\left(1-\pi_{t+1}\left(h \mid \ell, z^{t+1}\right)\right)\left(\frac{\epsilon_{\ell, t+1}\left(z^{t+1}\right)}{\epsilon_{\ell t}\left(z^{t}\right)}\right)^{-\sigma}$,

where $Q_{t+1}\left(z^{t+1}\right)$ is the Arrow-security price and $\lambda_{s_{t}, t+1}\left(z^{t+1}\right)$ is the Lagrange multiplier.

In the following, we will construct $\pi_{t+1}\left(s_{t+1} \mid s_{t}, z^{t+1}\right), \epsilon_{h t}\left(z^{t}\right)$, and $\epsilon_{\ell t}\left(z^{t}\right)$ that deliver a given $m_{t+1}\left(z^{t+1}\right)$. Consider the individual income levels

$$
\epsilon_{\ell t}\left(z^{t}\right)=2 \zeta C_{t}\left(z^{t}\right)
$$

and

$$
\epsilon_{h t}\left(z^{t}\right)=2(1-\zeta) C_{t}\left(z^{t}\right)
$$

where $\zeta \in(0,1)$. Later we will impose $\zeta<1 / 2$ so that $\epsilon_{h t}\left(z^{t}\right)>\epsilon_{\ell t}\left(z^{t}\right)$.

Suppose that the initial population of the consumers who have the initial endowment is $1 / 2$ for both $\ell$ and $h$. Further suppose that the idiosyncratic probabilities are such that the population of each endowment consumers remain as $1 / 2$ forever. (We will explicitly spell out this condition later.)

First, note that the individual endowment (30) and (31) are consistent with the 
definition of the aggregate endowment:

$$
C_{t}\left(z^{t}\right) \equiv \frac{\epsilon_{\ell_{t}}\left(z^{t}\right)}{2}+\frac{\epsilon_{h t}\left(z^{t}\right)}{2}=\zeta C_{t}\left(z^{t}\right)+(1-\zeta) C_{t}\left(z^{t}\right)
$$

We will select $\pi_{t+1}\left(h \mid \ell, z^{t+1}\right)$ so that the each endowment population is constant over time. This implies that

$$
\frac{1}{2}\left(1-\pi_{t+1}\left(h \mid h, z^{t+1}\right)\right)=\frac{1}{2} \pi_{t+1}\left(h \mid \ell, z^{t+1}\right) .
$$

Therefore,

$$
\pi_{t+1}\left(h \mid \ell, z^{t+1}\right)=1-\pi_{t+1}\left(h \mid h, z^{t+1}\right) .
$$

Thus, we automatically obtain $\pi_{t+1}\left(h \mid \ell, z^{t+1}\right)$ from this equation once $\pi_{t+1}\left(h \mid h, z^{t+1}\right)$ is assigned. Note that $\pi_{t+1}\left(h \mid \ell, z^{t+1}\right) \in[0,1]$ is ensured if $\pi_{t+1}\left(h \mid h, z^{t+1}\right) \in[0,1]$ is satisfied.

Inserting the income levels (30) and (31) into (28) and (29), we obtain

$$
\left(\frac{Q_{t+1}\left(z^{t+1}\right)}{\beta \phi_{z z^{\prime}}}-\frac{\lambda_{h, t+1}\left(z^{t+1}\right)}{\beta \phi_{z z^{\prime}} \epsilon_{h t}\left(z^{t}\right)^{-\sigma}}\right)\left(\frac{C_{t+1}\left(z^{t+1}\right)}{C_{t}\left(z^{t}\right)}\right)^{\sigma}=\pi_{t+1}\left(h \mid h, z^{t+1}\right)+\left(1-\pi_{t+1}\left(h \mid h, z^{t+1}\right)\right)\left(\frac{\zeta}{1-\zeta}\right)^{-\sigma}
$$

and

$$
\left(\frac{Q_{t+1}\left(z^{t+1}\right)}{\beta \phi_{z z^{\prime}}}-\frac{\lambda_{\ell, t+1}\left(z^{t+1}\right)}{\beta \phi_{z z^{\prime}} \epsilon_{\ell t}\left(z^{t}\right)^{-\sigma}}\right)\left(\frac{C_{t+1}\left(z^{t+1}\right)}{C_{t}\left(z^{t}\right)}\right)^{\sigma}=\pi_{t+1}\left(h \mid \ell, z^{t+1}\right)\left(\frac{1-\zeta}{\zeta}\right)^{-\sigma}+\left(1-\pi_{t+1}\left(h \mid \ell, z^{t+1}\right)\right) .
$$

Therefore, $\lambda_{\ell, t+1}\left(z^{t+1}\right)>0$ holds, and the low-endowment consumers are always borrowing constrained. This means that the high-endowment consumers' marginal rates of substitution determine the pricing kernel. The pricing kernel $m_{t+1}\left(z^{t+1}\right)$ is

$$
m_{t+1}\left(z^{t+1}\right)=\beta\left(\frac{C_{t+1}\left(z^{t+1}\right)}{C_{t}\left(z^{t}\right)}\right)^{-\sigma}\left[\pi_{t+1}\left(h \mid h, z^{t+1}\right)+\left(1-\pi_{t+1}\left(h \mid h, z^{t+1}\right)\right)\left(\frac{\zeta}{1-\zeta}\right)^{-\sigma}\right] .
$$

Thus, any

$$
m_{t+1}\left(z^{t+1}\right) \in\left[\beta\left(\frac{C_{t+1}\left(z^{t+1}\right)}{C_{t}\left(z^{t}\right)}\right)^{-\sigma}, \beta\left(\frac{C_{t+1}\left(z^{t+1}\right)}{C_{t}\left(z^{t}\right)}\right)^{-\sigma}\left(\frac{\zeta}{1-\zeta}\right)^{-\sigma}\right]
$$

can be chosen by picking $\pi_{t+1}\left(h \mid h, z^{t+1}\right) \in[0,1]$ appropriately, for a given $\zeta$. Note that we do not have any restriction on $\zeta$ at this point, other than $0<\zeta<1 / 2$. 
Pick $\zeta$ small enough so that

$$
\left(\frac{\zeta}{1-\zeta}\right)^{-\sigma} \geq \sup _{t, z^{t}, z^{t+1}} \frac{m_{t+1}\left(z^{t+1}\right)}{\beta\left(\frac{C_{t+1}\left(z^{t+1}\right)}{C_{t}\left(z^{t}\right)}\right)^{-\sigma}}
$$

is satisfied. Then, all $m_{t+1}\left(z^{t+1}\right) \geq \beta\left(\frac{C_{t+1}\left(z^{t+1}\right)}{C_{t}\left(z^{t}\right)}\right)^{-\sigma}$ at each $z^{t+1}$ can be achieved by selecting $\pi_{t+1}\left(h \mid h, z^{t+1}\right) \in[0,1]$ for each $z^{t+1}$ to satisfy (32) for this $\zeta$.

Proof of Proposition 7: $M_{i}$ can be rewritten as $M_{i}=-\beta \sum_{j=1}^{N} \pi_{i j}\left(-u^{\prime}\left(\epsilon_{j}\right) / u^{\prime}\left(\epsilon_{i}\right)\right)$. Clearly, $\left(-u^{\prime}\left(\epsilon_{j}\right) / u^{\prime}\left(\epsilon_{i}\right)\right)$ is increasing in $j$. From the definition of first-order stochastic dominance (see, for example, Mas-Colell, Whinston, and Green (1995, Definition 6.D.1)),

$$
\sum_{j=1}^{N} \hat{\pi}_{i j}\left(-\frac{u^{\prime}\left(\epsilon_{j}\right)}{u^{\prime}\left(\epsilon_{i}\right)}\right)>\sum_{j=1}^{N} \pi_{i j}\left(-\frac{u^{\prime}\left(\epsilon_{j}\right)}{u^{\prime}\left(\epsilon_{i}\right)}\right)
$$

holds. Therefore, $M_{i}$ is smaller for each $i=2, \ldots, N$ under $\hat{\pi}$ than under $\pi$. Since $M_{i}$ is smaller for each $i=2, \ldots, N, \max _{i=2, \ldots, N} M_{i}$ is also smaller.

Proof of Proposition 8: From the definition of $M_{i}$, it is sufficient to show that $H_{i}(\sigma) \equiv$ $\sum_{j=1}^{N} \pi_{i j}\left(\epsilon_{i} / \epsilon_{j}\right)^{\sigma}$ is increasing in $\sigma$ when $H_{i}(\sigma) \geq 1$ (since $H_{N}(\sigma) \geq 1$, it is always the case that $\left.\max _{i=2, \ldots, N} H_{i}(\sigma) \geq 1\right)$. Note that $\sigma \geq 0$ and $H_{i}(0)=1$. Let $\epsilon_{i} / \epsilon_{j}=k_{i j}$. Differentiating,

$$
H_{i}^{\prime}(\sigma)=\sum_{j=1}^{N} \pi_{i j} \log \left(k_{i j}\right)\left(k_{i j}\right)^{\sigma}
$$

and

$$
H_{i}^{\prime \prime}(\sigma)=\sum_{j=1}^{N} \pi_{i j}\left(\log \left(k_{i j}\right)\right)^{2}\left(k_{i j}\right)^{\sigma} .
$$

Since $H_{i}^{\prime \prime}(\sigma) \geq 0$ and $H_{i}(0)=1, H_{i}(\sigma)$ is always increasing for $\sigma \geq 0$ when $H_{i}(\sigma) \geq 1$.

Proof of Proposition 9: Equation (25) implies that for any $i=2, \ldots, N-1$,

$$
\sum_{j=1}^{N} \pi_{N j} \frac{u^{\prime}\left(\epsilon_{j}\right)}{u^{\prime}\left(\epsilon_{N}\right)} \geq \sum_{j=1}^{i-1} \pi_{i j} \frac{u^{\prime}\left(\epsilon_{j}\right)}{u^{\prime}\left(\epsilon_{N}\right)}+\sum_{j=i}^{N} \pi_{i j} .
$$


To see why this holds, note that the left-hand side can be rewritten as $\int_{0}^{1} F(x) d x$, where

$$
F(x) \equiv \begin{cases}\frac{u^{\prime}\left(\epsilon_{1}\right)}{u^{\prime}\left(\epsilon_{N}\right)} & \text { when } 0 \leq x \leq \pi_{N 1}, \\ \frac{u^{\prime}\left(\epsilon_{j}\right)}{u^{\prime}\left(\epsilon_{N}\right)} & \text { when } \sum_{k=1}^{j-1} \pi_{N k}<x \leq \sum_{k=1}^{j} \pi_{N k}, \text { where } 2 \leq j \leq N .\end{cases}
$$

The right-hand side can be rewritten as $\int_{0}^{1} G(x) d x$, where

$$
G(x) \equiv \begin{cases}\frac{u^{\prime}\left(\epsilon_{1}\right)}{u^{\prime}\left(\epsilon_{N}\right)} & \text { when } 0 \leq x \leq \pi_{i 1}, \\ \frac{u^{\prime}\left(\epsilon_{j}\right)}{u^{\prime}\left(\epsilon_{N}\right)} & \text { when } \sum_{k=1}^{j-1} \pi_{i k}<x \leq \sum_{k=1}^{j} \pi_{i k}, \text { where } 2 \leq j \leq i-1, \\ 1 & \text { when } \sum_{k=1}^{j-1} \pi_{i k}<x \leq \sum_{k=1}^{j} \pi_{i k}, \text { where } i \leq j \leq N .\end{cases}
$$

Equation (25) ensures that $F(x) \geq G(x)$ for all $x$.

The following can be verified by comparing term by term:

$$
\sum_{j=1}^{i-1} \pi_{i j} \frac{u^{\prime}\left(\epsilon_{j}\right)}{u^{\prime}\left(\epsilon_{N}\right)}+\sum_{j=i}^{N} \pi_{i j} \geq \sum_{j=1}^{N} \pi_{i j} \frac{u^{\prime}\left(\epsilon_{j}\right)}{u^{\prime}\left(\epsilon_{i}\right)} .
$$

From this and (33), we obtain

$$
\sum_{j=1}^{N} \pi_{N j} \frac{u^{\prime}\left(\epsilon_{j}\right)}{u^{\prime}\left(\epsilon_{N}\right)} \geq \sum_{j=1}^{N} \pi_{i j} \frac{u^{\prime}\left(\epsilon_{j}\right)}{u^{\prime}\left(\epsilon_{i}\right)}
$$

for any $i$, which is the desired inequality. 


\section{References}

[1] Alvarez, F. and U. Jermann (2000), "Efficiency, Equilibrium, and Asset Pricing with Risk of Default," Econometrica 68, 775-797.

[2] Alvarez, F. and U. Jermann (2001), "Quantitative Asset Pricing Implications of Endogenous Solvency Constraints," Review of Financial Studies 14, 1117-1151.

[3] Castañeda, Ana; Díaz-Giménez; and José-Víctor Ríos-Rull (2003). "Accounting for the U.S. Earnings and Wealth Inequality," Journal of Political Economy 111, 818-857.

[4] Cochrane, John H. (2001). Asset Pricing, Princeton: Princeton University Press.

[5] Constantinides, George M., and Darrell Duffie (1996). "Asset Pricing with Heterogeneous Consumers," Journal of Political Economy 104, 219-240.

[6] Den Haan, Wouter J. (1996). "Heterogeneity, Aggregate Uncertainty, and the Short Term Interest Rate," Journal of Business and Economic Statistics 14, 399-411.

[7] Floden, Martin and Jasper Lindé (2001). "Idiosyncratic Risk in the United States and Sweden: Is There a Role for Government Insurance?" Review of Economic Dynamics 4, 406-437.

[8] Heaton, John and Deborah J. Lucas (1992), "The Effects of Incomplete Insurance Markets and Trading Costs in a Consumption-Based Asset Pricing Model," Journal of Economic Dynamics and Control 16, 601-620.

[9] Heaton, John and Deborah J. Lucas (1996), "Evaluating the Effects of Incomplete Markets on Risk Sharing and Asset Pricing," Journal of Political Economy 104, $443-487$.

[10] Huggett, Mark (1993), "The Risk-Free Rate in Heterogeneous-Agent IncompleteInsurance Economies," Journal of Economic Dynamics and Control 17, 953-969. 
[11] Krueger, Dirk and Hanno Lustig (2007), "When is Market Incompleteness Irrelevant for the Price of Aggregate Risk?" mimeo. University of Pennsylvania and UCLA.

[12] Krusell, Per and Anthony A. Smith, Jr. (1997), "Income and Wealth Heterogeneity, Portfolio Choice and Equilibrium Asset Returns," Macroeconomic Dynamics $1,387-422$.

[13] Krusell, Per and Anthony A. Smith, Jr. (1998), "Income and Wealth Heterogeneity in the Macroeconomy," Journal of Political Economy 106, 867-896.

[14] Krusell, Per and Anthony A. Smith, Jr. (1999), "On the Welfare Effects of Eliminating Business Cycles," Review of Economic Dynamics 2, 245-272.

[15] Leduc, Sylvain (2002), "Incomplete Markets, Borrowing Constraints, and the Foreign Exchange Risk Premium," Journal of International Money and Finance 21, 957-80.

[16] Lucas, Deborah J. (1994), “Asset Pricing with Undiversifiable Income Risk and Short Sales Constraints: Deepening the Equity Premium Puzzle," Journal of Monetary Economics 34, 325-341.

[17] Lucas, Robert E., Jr. (1978), "Asset Prices in an Exchange Economy," Econometrica 46, 1429-1445.

[18] Mankiw, N. Gregory (1986), "The Equity Premium and the Concentration of Aggregate Shocks," Journal of Financial Economics 17, 211-219.

[19] Marcet, Albert and Kenneth J. Singleton (1999), "Equilibrium Asset Prices and Savings of Heterogeneous Agents in the Presence of Incomplete Markets and Portfolio Constraints" Macroeconomic Dynamics 3, 243-276.

[20] Mas-Colell, Andreu; Michael D. Whinston; and Jerry R. Green (1995), Microeconomic Theory, New York: Oxford University Press. 
[21] Mehra, Rajnish and Edward C. Prescott (1985), "The Equity Premium: A Puzzle," Journal of Monetary Economics 15, 145-162.

[22] Rodríguez, S.B., J. Díaz-Giménez, V. Quadrini, and J.-V. Ríos-Rull (2002), "Updated Facts on the U.S. Distributions of Earnings, Income, and Wealth," Federal Reserve Bank of Minneapolis Quarterly Review 26 (No. 3), 2-35.

[23] Shimer, Robert (2005), "The Cyclical Behavior of Equilibrium Unemployment and Vacancies," American Economic Review 95, 25-49.

[24] Storesletten, Kjetil; Christopher I. Telmer; and Amir Yaron (2007), "Asset Pricing with Idiosyncratic Risk and Overlapping Generations," Review of Economic Dynamics 10, 519-548.

[25] Tauchen, George (1986), "Finite State Markov-chain Approximations to Univariate and Vector Autoregressions." Economics Letters 20, 177-181.

[26] Telmer, Christopher I. (1993), "Asset-Pricing Puzzles and Incomplete Markets," Journal of Finance 48, 1803-1832.

[27] Weil, Philippe (1989), "The Equity Premium Puzzle and the Risk-Free Rate Puzzle." Journal of Monetary Economics 24, 401-421. 